(C) 2020, The Authors. Published by Elsevier Inc. and Fass Inc. on behalf of the American Dairy Science Association ${ }^{\circledR}$. This is an open access article under the CC BY-NC-ND license (http://creativecommons.org/licenses/by-nc-nd/4.0/).

\title{
The association of cow-related factors assessed at metritis diagnosis with metritis cure risk, reproductive performance, milk yield, and culling for untreated and ceftiofur-treated dairy cows
}

\author{
V. S. Machado, ${ }^{1 *}$ M. L. Celestino, ${ }^{1}$ E. B. Oliveira, ${ }^{2,3}$ F. S. Lima,${ }^{3}$ M. A. Ballou, ${ }^{1}$ and K. N. Galvão ${ }^{2,4}$ \\ ${ }^{1}$ Department of Veterinary Sciences, College of Agricultural Sciences and Natural Resources, Texas Tech University, Lubbock 79409 \\ ${ }^{2}$ Department of Large Animal Clinical Sciences, College of Veterinary Medicine, University of Florida, Gainesville 32611-0910 \\ ${ }^{3}$ Department of Population Health and Reproduction, School of Veterinary Medicine, University of California, Davis 95616 \\ ${ }^{4}$ D. H. Barron Reproductive and Perinatal Biology Research Program, University of Florida, Gainesville 32610
}

\begin{abstract}
Our objective was to assess the association of cowrelated factors with metritis cure risk and economically important outcomes. In this prospective cohort study nested inside a randomized clinical trial, cows enrolled in a clinical trial that aimed to evaluate an alternative metritis therapy that had available plasma samples collected at metritis diagnosis were included. Metritis was defined as fetid, watery, reddish-brownish discharge with or without fever, and cure was defined as the absence of metritis signs $12 \mathrm{~d}$ after diagnosis. Cows were randomly allocated to remain untreated $(\mathrm{CON} ; \mathrm{n}=$ 147) or receive subcutaneous injections of $6.6 \mathrm{mg} / \mathrm{kg}$ of ceftiofur crystalline-free acid at enrollment and 72 $\mathrm{h}$ later $(\mathrm{CEF}, \mathrm{n}=168)$. Additionally, a random subset of 150 nonmetritic cows (NMET) was also included to compare milk production, reproductive performance, and culling responses. Cow-related factors evaluated include plasma concentrations of nonesterified fatty acids, $\beta$-hydroxybutyrate, and haptoglobin (Hp), parity, rectal temperature, and days in milk (DIM) at metritis diagnosis, vulvovaginal laceration (VL), BCS, dystocia, twins, and retained placenta. Among CON cows, DIM at metritis diagnosis was positively associated with metritis cure [threshold $=8$, area under the curve (AUC) $=0.67$, whereas plasma Hp concentration tended to be negatively associated with cure of metritis (threshold $=0.54 \mathrm{mg} / \mathrm{mL}, \mathrm{AUC}=0.64)$. Among CEF cows, DIM at metritis diagnosis (threshold $=5, \mathrm{AUC}=0.67$ ) and dystocia were positively associated with metritis cure, whereas VL and Hp (threshold $=0.78 \mathrm{mg} / \mathrm{mL}$, AUC $=0.76$ ) were negatively associated with cure. For CON cows that were diagnosed with metritis after 8 DIM or had plasma Hp concentration $\leq 0.54 \mathrm{mg} / \mathrm{mL}$, milk pro-
\end{abstract}

Received April 3, 2020.

Accepted May 31, 2020

*Corresponding author: vinicius.machado@ttu.edu duction, pregnancy, and culling risk were comparable to NMET cows. However, performance was impaired when cows that developed metritis at $\leq 8$ DIM or had Hp $>0.54 \mathrm{mg} / \mathrm{mL}$ were left untreated. Among CEF cows, Hp, DIM at metritis diagnosis, dystocia, and VL were associated with metritis cure. Milk yield, reproductive performance, and culling losses are more pronounced among CEF cows when metritis was diagnosed at $\leq 5$ DIM, Hp $>0.78 \mathrm{mg} / \mathrm{mL}$, or if they had VL or dystocia. In conclusion, these data indicate that timing of the onset of metritis and inflammatory biomarkers could be used for the development of a selective therapy strategy for metritis, but more research is needed to identify more accurate predictors of metritis spontaneous cure and treatment failure.

Key words: metritis, cure, haptoglobin, selective therapy

\section{INTRODUCTION}

Metritis is a painful, prevalent postpartum uterine disease that is characterized by an abnormally enlarged uterus and a fetid, watery, red-brown uterine discharge within $21 \mathrm{~d}$ after parturition, with its incidence peaking within the first $10 \mathrm{~d}$ postpartum (Sheldon et al., 2006; LeBlanc et al., 2011; Stojkov et al., 2015). Metritis is a complex multifactorial disease, caused by a mixed bacterial infection, with Escherichia coli, Fusobacterium necrophorum, Bacteroides spp., and Trueperella pyogenes being the most relevant pathogens associated with postpartum uterine infections (Bicalho et al., 2012; Jeon et al., 2015). The effect of metritis on productivity is striking. Cows that experience metritis have decreased milk production and poor fertility, and are more likely to be culled (Wittrock et al., 2011; Giuliodori et al., 2013; Stangaferro et al., 2016). The economic losses caused by each metritis case have been recently calculated at US $\$ 267$ to 410 due to antibiotic treatment and the detrimental effects of metritis on 
reproductive performance, milk production, and culling (Lima et al., 2019). Hence, metritis is extensively monitored and treated by dairy producers (Espadamala et al., 2018).

Currently, the most common antimicrobial drug used to treat metritis in the United States is ceftiofur. It has been described that $73.9 \%$ of studies evaluating metritis treatment efficacy used ceftiofur as their drug of choice (Haimerl and Heuwieser, 2014), and more than $60 \%$ of dairy producers from the state of California use systemic ceftiofur administration to treat metritis (Espadamala et al., 2018). However, new regulations from countries in Europe have limited its use in livestock. Ceftiofur is an efficacious drug to treat metritis, as it increases metritis clinical cure by approximately 20\% (Chenault et al., 2004; McLaughlin et al., 2013). Additionally, ceftiofur-treated cows had increased milk yields during the first 2 mo of lactation and had improved fertility compared with untreated animals (Oliveira et al., 2020). However, it is important to highlight that more than half of the cows diagnosed with metritis undergo spontaneous cure (Chenault et al., 2004; McLaughlin et al., 2013; Oliveira et al., 2020). Given that ceftiofur belongs to a class of antibiotics (third generation cephalosporins) that are considered of critical importance in human medicine and that antimicrobial resistance has become a major public and animal health concern (Dolejska et al., 2011), its use in dairy cows should be more rational. Identifying factors associated with metritis cure that can predict the likelihood of cows benefiting from antimicrobial therapy will be important for the development of a selective therapy for metritis that reduces the use of antibiotics on dairy farms while maintaining animal health.

Selective therapy strategies are not novel in dairy cattle medicine management. For instance, this approach is currently adopted for clinical mastitis therapy and takes into consideration bacteriological findings from milk samples to determine which cases of clinical mastitis will likely benefit from antimicrobial therapy. In metritis cases, the host immune response was more closely associated with disease severity than the intrauterine microbiome (Jeon et al., 2016). Thus, we hypothesized that cow-related factors are more likely to be associated with cure than bacteriological findings. Information regarding factors associated with metritis severity and likelihood of cure is scarce. Cow-related factors such as parity, retained placenta $(\mathbf{R P})$, and calving abnormalities (e.g., dystocia, twins, and vulvovaginal laceration, VL) are known risk factors for metritis and could potentially be predictive of cure (Lima et al., 2014; Vergara et al., 2014; Vieira-Neto et al., 2016). Additionally, elevated concentrations of markers of metabolic imbalance such as nonesterified fatty acids (NEFA) and BHB, have been associated with increased risk of metritis (Hammon et al., 2006; Dubuc et al., 2010; Ospina et al., 2010; Bicalho et al., 2014) and may help predict metritis cure. The circulating concentration of the acute phase protein haptoglobin (Hp) was associated with metritis severity (Huzzey et al., 2009), and its value as an indicator of metritis cure likelihood warrants further investigation.

Therefore, the first objective of this study was to evaluate the association between cow-related factors with likelihood of metritis cure. Our second objective was to evaluate how these cow-related factors affect reproductive performance, culling, and milk yield of metritic cows compared with nonmetritic (NMET) animals.

\section{MATERIALS AND METHODS}

\section{Metritis Diagnosis, Inclusion Criteria, Treatment Groups, and Farm Management}

To conduct the present study, data generated by a clinical trial that aimed to investigate the efficacy of intrauterine administration of chitosan microparticles $(\mathbf{C M})$ as an alternative therapy for metritis (Oliveira et al., 2020) were used. Hence, this was a prospective cohort study nested inside a randomized clinical trial. Metritis incidence was monitored by examining vaginal discharge using the Metricheck device (Simcro, Hamilton, NZ) at 5, 7, and 9 DIM. Additionally, cows with signs of systemic illness (lack of appetite, dullness, decreased milk production) identified by farm employees also had their vaginal contents examined; hence, cows could be diagnosed with metritis on days other than 5, 7, and 9 DIM. Vaginal discharge was scored using a modified 1 to 5 scale: $1=$ not fetid clear mucoid discharge; $2=$ not fetid cloudy mucoid discharge with flecks of pus; $3=$ not fetid, mucopurulent discharge with $<50 \%$ pus; $4=$ not fetid mucopurulent white, yellow, or reddish-brownish discharge with $\geq 50 \%$ pus; and 5 $=$ fetid, thin, serous, or watery, reddish-brownish, with or without pieces of necrotic tissue present (Oliveira et al., 2020). Cows that had a score of 5 were classified as having metritis.

In the previous field study used to extract the current data for analysis (Oliveira et al., 2020), a total of 826 cows from 3 different farms diagnosed with metritis (fetid, thin, reddish-brownish discharge) were randomly allocated into 3 different treatment groups: (1) CM, intrauterine infusion of $24 \mathrm{~g}$ of CM dissolved in $40 \mathrm{~mL}$ of sterile distilled water on metritis diagnosis/enrollment, and 2 and $4 \mathrm{~d}$ later; (2) CEF, subcutaneous injections of $6.6 \mathrm{mg} / \mathrm{kg}$ of ceftiofur crystalline-free acid (Excede, Zoetis, Florham Park, NJ) at enrollment and $72 \mathrm{~h}$ later; 
and (3) CON, untreated controls. Additionally, 2,436 cows were classified as NMET. These cows had a vaginal score $<4$ at 5,7 , and 9 DIM, and were not identified by the farm employees as metritis case suspects.

Because CM was not an efficacious therapy for metritis and seemed to aggravate metritis severity in some cases, only cows enrolled in the CEF or CON groups were eligible to be included in the present study. Additionally, cows were included herein based on the availability of plasma sample collected at enrollment or metritis diagnosis. Blood samples were collected from a random subset of cows enrolled in Oliveira et al. (2020) to evaluate the effect of metritis treatment on blood concentrations of BHB, NEFA, and Hp. Only cows from one farm were included in this study because they comprised the most cows that had available plasma samples collected at enrollment. We performed our sample size calculation based on our primary hypothesis that at least one of the continuous variables analyzed here would be associated with spontaneous cure or treatment failure. Hence, we performed a sample size calculation using the "area under ROC curve" sample size calculation tool in MedCalc version 18.11.6 software (MedCalc Software, Mariakerke, Belgium). It was calculated based on the assumption that a receiver operating characteristic (ROC) curve would classify half of the untreated cows as "likely to recover" from metritis and one-third of the treated cows as "treatment failure." Hence, we determined that at least 114 and 147 cows in CON and CEF group, respectively, would be necessary to observe an area under the curve $(\mathbf{A U C})=0.65$, assuming a null hypothesis of AUC $=0.50$, a type I error of 0.05 , and a type II error of 0.20 . Therefore, 147 and 168 cows enrolled in treatment groups CON and CEF, respectively, were included in this study. Furthermore, a random subset of 150 NMET cows was also included in the study to compare milk production, reproductive performance, and culling responses. Nonmetritic cows were selected to match their respective parity block in cows diagnosed with metritis. The population of ani-

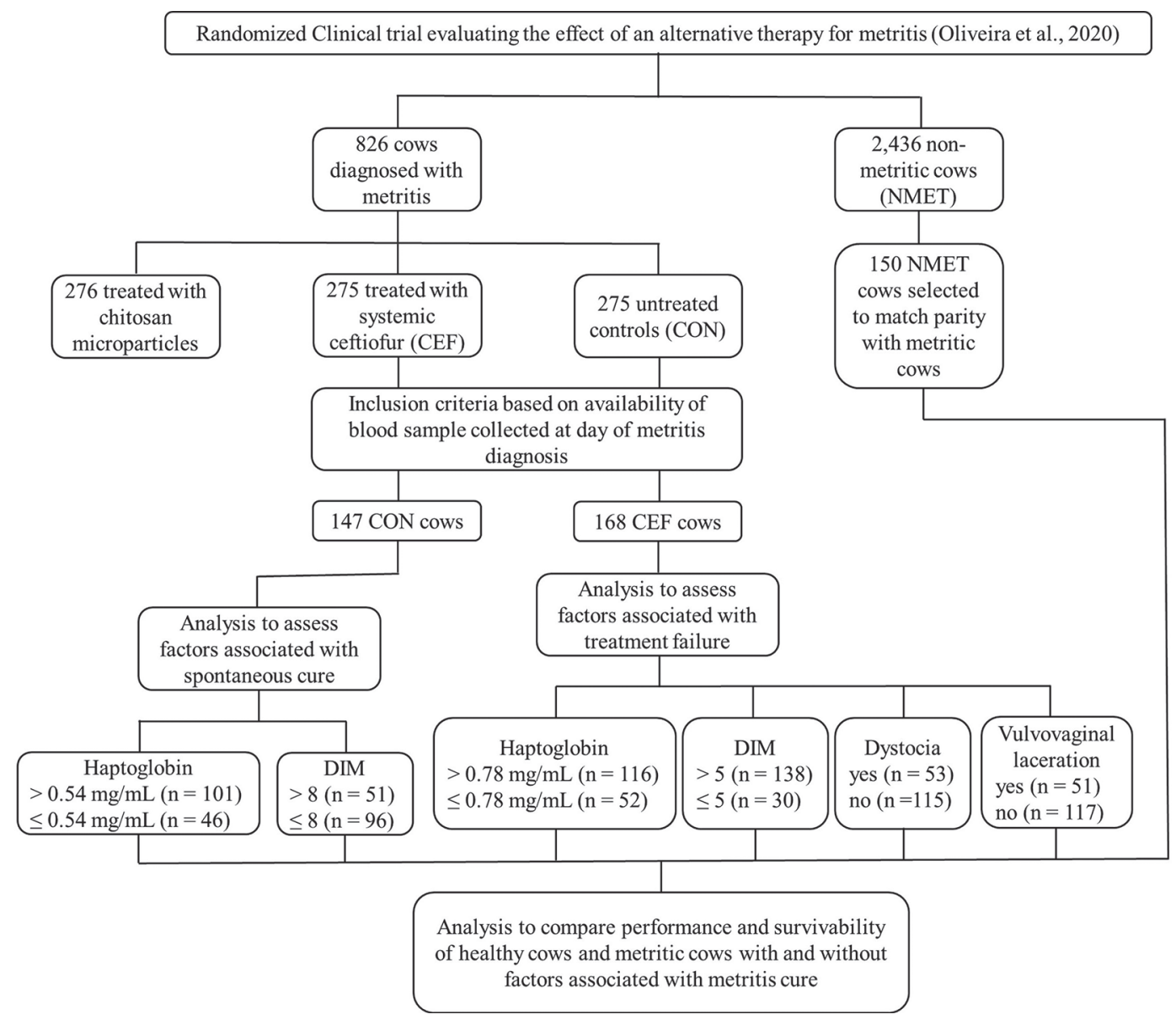

Figure 1. Chart describing the animals included and analyses performed in this study. 
mals included and analyses performed in this study are described in Figure 1.

Cows included in this study were housed in a dairy farm located in North Central Florida that milks 4,400 cows 3 times daily. Cows were housed in freestall sand-bedded pens and were fed a TMR ad libitum formulated to meet or exceed the NRC (2001) nutrient requirements for lactating Holstein cows weighing $680 \mathrm{~kg}$ and producing $45 \mathrm{~kg}$ of $3.5 \% \mathrm{FCM}$ and $3.0 \%$ protein. Reproductive management used a combination of detection of estrus using a heat detection device (Kamar, Kamar Inc., Steamboat Springs, CO), Presynch, Ovsynch, and Resynch. The voluntary waiting period was 48 DIM, when cows were eligible to be inseminated upon estrus detection. Cows that were not inseminated by $55 \pm 3$ DIM were administered $\mathrm{PGF}_{2 \alpha}$ and inseminated upon estrus detection. Ovsynch protocol was initiated at $72 \pm 3$ DIM to all cows that were not inseminated upon estrus detection. For those cows, fixed-time AI was performed at $82 \pm 3$ DIM. Pregnancy diagnosis was performed at $33 \pm 3 \mathrm{~d}$ after service, and resynchronization using Ovsynch was performed to all nonpregnant cows.

\section{Metritis Cure Definition and Data Collection}

At 12 d after metritis diagnosis, vaginal discharge was re-examined using the Metricheck device. Cure of metritis was defined as vaginal discharge score $<5$. Cows that were culled or died before 12 after enrollment were considered as noncured. Additionally, escape therapy with antimicrobial drugs was allowed for both treatment groups, and it was administered based on signs of severe dehydration, inappetence, or other systemic signs due to metritis. The need for escape therapy was decided by farm personnel without consulting the research team. Farm personnel were unaware of treatment allocation. Cows were eligible to receive escape therapy $1 \mathrm{~d}$ after enrollment. Cows that received escape therapy were also considered as noncured from metritis.

At enrollment and at 3, 6, 9, and 12 d later, rectal temperature was evaluated using a digital thermometer. Additionally, at 5 DIM, BCS was evaluated on a 5 -point scale as previously described (Edmonson et al., 1989). The VL was scored at 5 DIM as $0=$ no laceration; 1 = laceration $<2 \mathrm{~cm}$ at dorsal commissure or internal vaginal wall; and $2=$ vaginal-vulvar laceration $>2 \mathrm{~cm}$ (Vieira-Neto et al., 2016). Vulvovaginal laceration presence was defined when VL score $=2$.

Data regarding parity, DIM at metritis diagnosis, dystocia, twinning, RP, culling, reproductive performance, and milk production were extracted using the farm's database software PCDart (Dairy Records Management Systems, Raleigh, NC).

\section{Blood Collection and Analysis}

Blood samples were collected at enrollment by puncture of the coccygeal vessels using a vacutainer tube with potassium EDTA, and a 20-gauge $\times 2.54-\mathrm{cm}$ vacutainer needle (Becton, Dickinson and Company, Franklin Lakes, NJ). The blood samples were transported to the laboratory on ice, and centrifuged at $2,000 \times g$ for 10 min at $4^{\circ} \mathrm{C}$. The plasma was harvested and frozen at $-80^{\circ} \mathrm{C}$ until further analyses were conducted.

Plasma Hp concentration was determined using a colorimetric assay via quantification of the $\mathrm{Hp} /$ hemoglobin complex by the estimation of differences in peroxidase activity (Makimura and Suzuki, 1982). Assays were performed in $16 \times 100$ borosilicate tubes. Briefly, $5 \mu \mathrm{L}$ of serum sample or deionized water (blank) were added to $7.5 \mathrm{~mL}$ of a solution containing $0.6 \mathrm{~g} / \mathrm{L}$ of $\mathrm{O}$ dianisidine, $13.8 \mathrm{~g} / \mathrm{L}$ of sodium phosphate monobasic, and $0.5 \mathrm{~g} / \mathrm{L}$ EDTA $(\mathrm{pH}=4.1)$. Immediately, $25 \mu \mathrm{L}$ of $0.3 \mathrm{~g} / \mathrm{L}$ bovine hemoglobin solution was added to each assay, followed by a water bath incubation at $37^{\circ} \mathrm{C}$ for $45 \mathrm{~min}$. After incubation, $100 \mu \mathrm{L}$ of freshly prepared $156 \mathrm{~m} M$ hydrogen peroxidase solution was added to each assay. Samples were incubated at room temperature for $60 \mathrm{~min}$. Then, $200 \mu \mathrm{L}$ of each assay was transferred to a 96 -well polystyrene flat-bottom microplate. Optical density (OD) at $450 \mathrm{~nm}$ was measured on the Epoch2 Microplate Spectrophotometer (BioTek, Winooski, VT). Finally, the final OD of each assay was subtracted by the blank assay OD. Optical density data were converted to a concentration unit $(\mu \mathrm{g} / \mathrm{mL})$ using standard curves generated by serial dilutions of a sample of known concentration determined by a commercially available ELISA kit following the manufacturer's instructions (Life Technologies, West Chester, PA) as previously described (Cooke and Arthington, 2013). The intra- and interassay coefficients of variation for serum Hp were $6.9 \%$ and $7.7 \%$, respectively. Furthermore, plasma concentrations of NEFA and BHB were analyzed by a chemistry analyzer (RX DaytoNa ${ }^{+}$; Randox Laboratories Ltd., Kearneysville, WV) in a single assay, and the interassay coefficients of variation were $5.1 \%$ and $4.2 \%$ for NEFA and BHB, respectively.

\section{Statistical Analysis}

Descriptive statistics analysis regarding number of animals enrolled, metritis cure, parity, dystocia, twin parturition, RP, DIM at enrollment, BCS, VL, and plasma concentrations of NEFA, BHB, and Hp of cows enrolled in $\mathrm{CON}$ and $\mathrm{CEF}$ treatment groups was undertaken using the chi-squared and ANOVA functions of JMP 14 (SAS Institute Inc., Cary, NC). To assess the variables associated with metritis cure, a logistic 
Table 1. Descriptive statistics of metritic and nonmetritic (NMET) cows

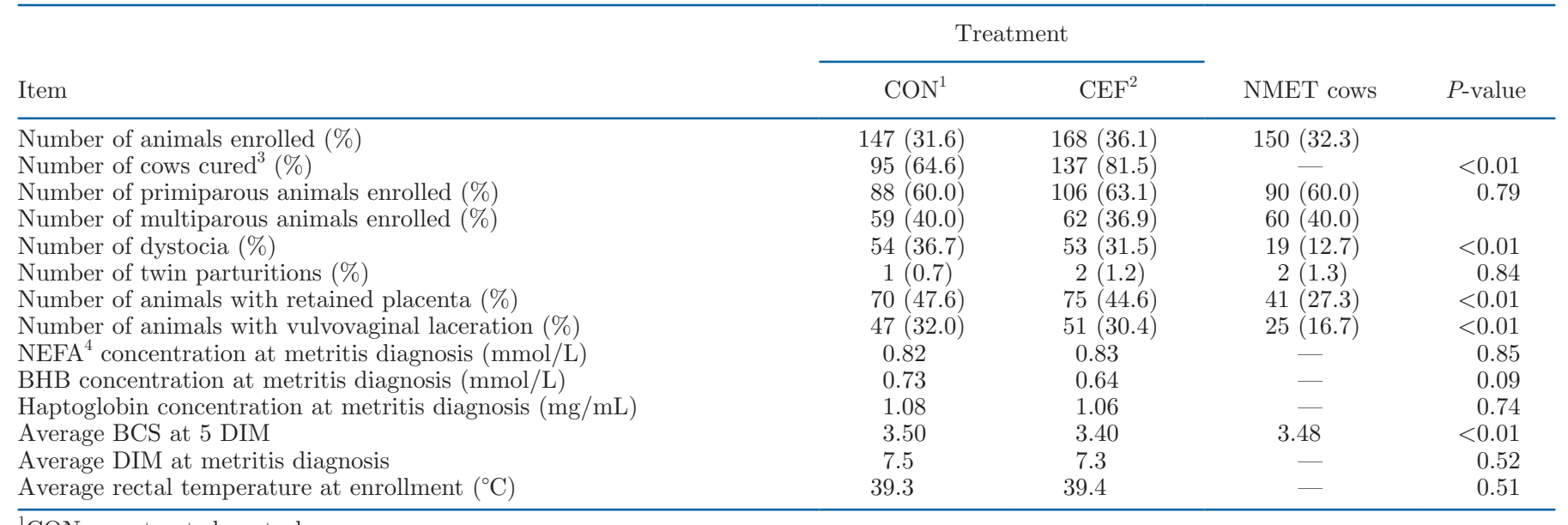

${ }^{1} \mathrm{CON}=$ untreated controls.

${ }^{2} \mathrm{CEF}=$ subcutaneous administration of $6.6 \mathrm{mg}$ of ceftiofur crystalline-free acid/kg of BW administered at metritis diagnosis and $72 \mathrm{~h}$ later.

${ }^{3}$ Absence of fetid watery vaginal discharge $12 \mathrm{~d}$ after enrollment.

${ }^{4} \mathrm{NEFA}=$ nonesterified fatty acids.

regression model was fitted in SAS using PROC GLIMMIX in SAS 9.4 (SAS Institute Inc.), and the independent categorical (treatment, parity, dystocia, twin parturition, RP, VL) and continuous variables (BCS, DIM at metritis diagnosis, and blood concentrations of NEFA, BHB, and $\mathrm{Hp}$ at metritis diagnosis) were offered to the model. A manual backward stepwise selection procedure was used, and variables were retained in the model if $P \leq 0.10$. To evaluate the hierarchical order of factors associated with metritis cure among all cows, partition analysis was performed in JMP. The dependent variable in this model was metritis cure, and the independent variables offered to the previously described logistic regression model were also offered to the partition analysis. The partition analysis creates a decision tree based on the relationship between predictor and response variables, using a partition algorithm that splits the data in a hierarchal manner (Kass, 1980).

Additionally, to assess the variables associated with metritis cure among CON and CEF cows, we stratified our analysis by treatment group. Hence, a logistic regression model was fitted in SAS using PROC GLIMMIX in SAS to assess the association of the independent variables parity, dystocia, twin parturition, RP, VL, BCS, DIM at metritis diagnosis, NEFA, BHB, and $\mathrm{Hp}$ with metritis cure for each treatment group. A manual backward stepwise selection procedure was used as described above. For continuous variables that were retained in the previous logistic regression models, ROC curves were performed on MedCalc to determine the most accurate threshold to predict metritis cure
Table 2. Logistic regression models showing the association of cowrelated factors assessed at metritis diagnosis for all cows (model 1), untreated (model 2), and ceftiofur-treated (model 3) cows with metritis cure ${ }^{1}$

\begin{tabular}{lcc}
\hline Model and variables & Coefficient (SE) & $P$-value \\
\hline Model 1 (all metritic cows) & $0.36(0.79)$ & \\
Intercept & $-0.73(0.19)$ & $<0.01$ \\
$\mathrm{Hp}^{2}$ & $0.28(0.09)$ & $<0.01$ \\
DIM & $-0.86(0.28)$ & $<0.01$ \\
Treatment & Referent & \\
CON $^{3}$ & & \\
CEF $^{4}$ & $-0.55(0.31)$ & 0.07 \\
Dystocia & Referent & \\
No & & \\
Yes & $0.51(0.30)$ & 0.08 \\
Vulvovaginal laceration & Referent & \\
No & & \\
Yes & $-1.06(1.00)$ & 0.29 \\
Model 2 (CON) & $-0.43(0.27)$ & 0.10 \\
Intercept & $0.30(0.12)$ & 0.01 \\
Hp & & \\
DIM & $0.72(1.16)$ & 0.53 \\
Model 3 (CEF) & $-1.05(0.30)$ & $<0.01$ \\
Intercept & $0.27(0.14)$ & 0.05 \\
Hp & & \\
DIM & $-0.98(0.52)$ & 0.06 \\
Dystocia & Referent & \\
No & $1.28(0.46)$ & $<0.01$ \\
Yes & Referent & \\
Vulvovaginal laceration & No & \\
Yes & & \\
\hline Cure & &
\end{tabular}

${ }^{1}$ Cure was defined as absence of fetid watery vaginal discharge $12 \mathrm{~d}$ after enrollment.

${ }^{2} \mathrm{Hp}=$ haptoglobin.

${ }^{3} \mathrm{CON}=$ untreated controls

${ }^{4} \mathrm{CEF}=$ subcutaneous administration of $6.6 \mathrm{mg}$ of ceftiofur crystallinefree acid $/ \mathrm{kg}$ of $\mathrm{BW}$ administered at metritis diagnosis and $72 \mathrm{~h}$ later. 


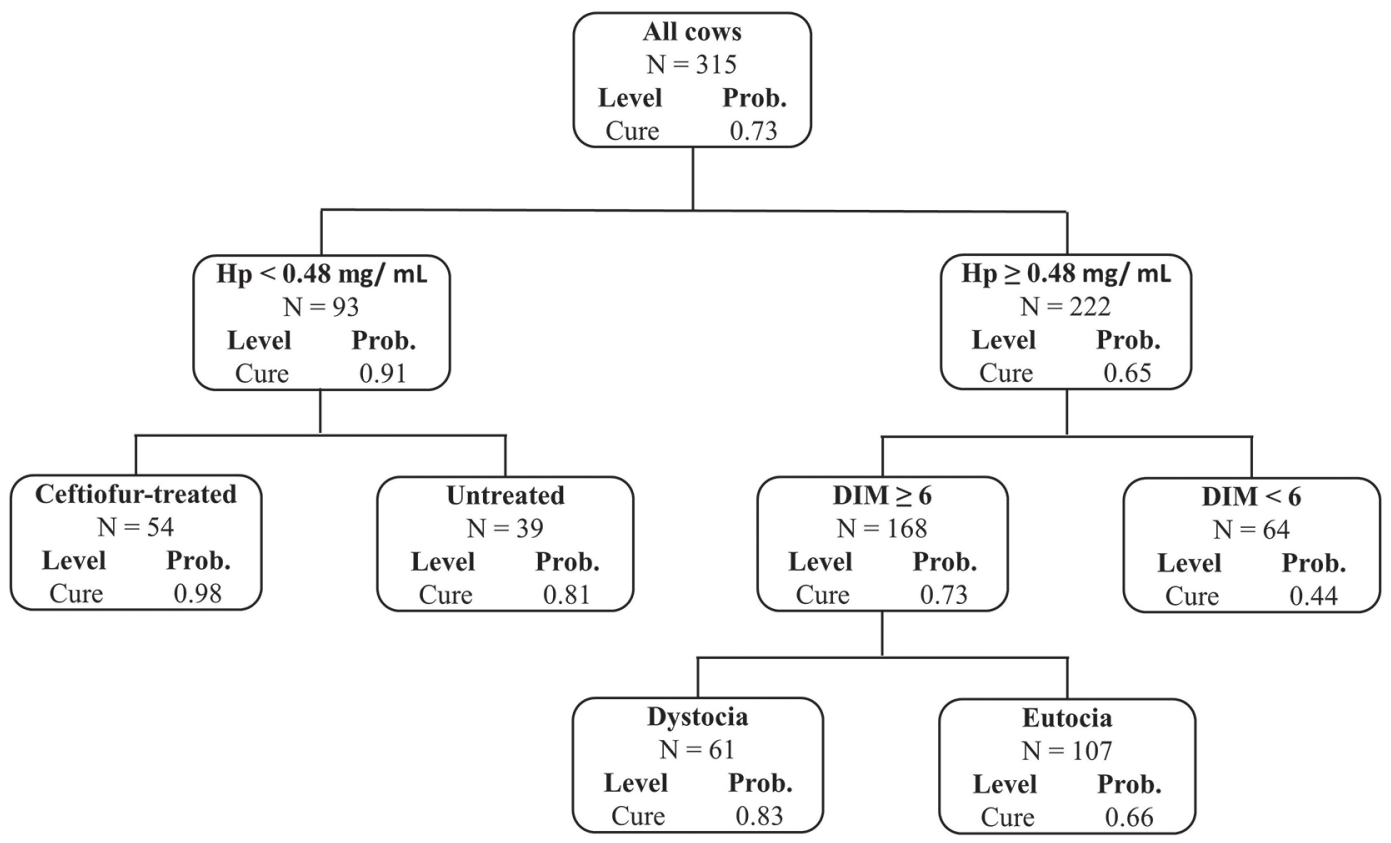

Figure 2. Partition analysis decision tree illustrating the hierarchical order of factors associated with metritis cure evaluated $12 \mathrm{~d}$ after initial diagnosis. The dependent variable included in the model was cure, and the independent variables offered to the analysis were treatment (untreated or ceftiofur treated), plasma concentrations of haptoglobin (Hp), BHB, and nonesterified fatty acids, parity, dystocia, twin parturition, retained placenta, vulvovaginal laceration, BCS, and DIM at metritis diagnosis. This analysis indicates that plasma Hp, DIM at metritis diagnosis, treatment, and dystocia were the first, second, third, and fourth most relevant predictors of metritis cure. Prob. = probability.

for each treatment group. Then, independent variables retained in the previous models, including categorical and newly dichotomized variables, and potential 2-way interactions were offered logistic regression models built to evaluate the association between cow-related factors and the odds of metritis cure. Independent variables and their respective interactions were removed from the models manually and in a stepwise manner when $P \leq$ 0.10 .

To understand how these cow-related factors among metritic cows affected reproductive performance, culling, and milk yield in relation to NMET animals, a series of multivariable models, including NMET animals, were fitted to the data. To assess the association between cow-related factors with the likelihood of conceiving, and likelihood of being culled or dead, multiple multivariable Cox's proportional hazard models were fitted using the PHREG procedure in SAS. For analysis of reproduction, cows were right-censored if not diagnosed as being pregnant before culling, death, or until 180 DIM. For analysis of survival, cows were rightcensored if they were alive at the end of the data collection period (300 DIM). To illustrate the median calving to conception interval, and the median time to culling

Table 3. Outcome of 4 receiver operating characteristic curve analyses performed to evaluate the optimum threshold of haptoglobin (Hp) and DIM at metritis diagnosis associated with metritis cure for untreated and ceftiofur-treated cows $(P<0.01$ for all models $)$

\begin{tabular}{|c|c|c|c|c|c|c|c|c|c|}
\hline Treatment $^{1}$ & Variable & $\mathrm{AUC}^{2}$ & Threshold & $\begin{array}{l}\% \text { cows below } \\
\text { threshold (n) }\end{array}$ & $\begin{array}{l}\% \text { cows above } \\
\text { threshold (n) }\end{array}$ & $\mathrm{Se}^{3}$ & $\mathrm{Sp}^{4}$ & $\mathrm{PPV}^{5}$ & $\mathrm{NPV}^{6}$ \\
\hline $\mathrm{CON}$ & $\mathrm{Hp}$ & 0.64 & $\leq 0.54 \mathrm{mg} / \mathrm{mL}$ & $31.3(46)$ & 68.7 (101) & 38.9 & 82.7 & 80.4 & 42.6 \\
\hline $\mathrm{CEF}$ & DIM & 0.67 & $>5$ & $17.9(30)$ & 82.1 (138) & 88.2 & 43.7 & 87.0 & 46.7 \\
\hline
\end{tabular}

${ }^{1} \mathrm{CON}=$ untreated controls; $\mathrm{CEF}=$ subcutaneous administration of $6.6 \mathrm{mg}$ of ceftiofur crystalline-free acid $/ \mathrm{kg}$ of $\mathrm{BW}$ administered at metritis diagnosis and $72 \mathrm{~h}$ later.

${ }^{2} \mathrm{AUC}=$ area under the curve

${ }^{3} \mathrm{Se}=$ sensitivity.

${ }^{4} \mathrm{Sp}=$ specificity

${ }^{5} \mathrm{PPV}=$ positive predictive value.

${ }^{6} \mathrm{NPV}=$ negative predictive value. 
Table 4. Association of cow-related factors assessed at metritis diagnosis, including dichotomized haptoglobin $(\mathrm{Hp})$ and DIM, for untreated (model 1) and ceftiofur-treated (model 2) cows with metritis cure odds ${ }^{1,2}$

\begin{tabular}{|c|c|c|c|c|}
\hline Model and variables & Coefficient (SE) & Odds ratio $(95 \% \mathrm{CI})$ & Adjusted cure (\%) & $P$-value \\
\hline \multicolumn{5}{|l|}{ Model 1 (CON) } \\
\hline Intercept & $2.04(0.47)$ & & & $<0.01$ \\
\hline \multicolumn{5}{|l|}{$\mathrm{Hp}(\mathrm{mg} / \mathrm{mL})$} \\
\hline$\leq 0.54(\mathrm{n}=46)$ & $0.80(0.47)$ & $2.22(0.87-5.66)$ & 81.2 & 0.09 \\
\hline$>0.54(\mathrm{n}=101)$ & Referent & Baseline & 66.1 & \\
\hline \multicolumn{5}{|l|}{ DIM } \\
\hline$\leq 8(\mathrm{n}=96)$ & Referent & Baseline & 62.0 & 0.01 \\
\hline$>8(\mathrm{n}=51)$ & $1.16(0.46)$ & $3.20(1.27-8.02)$ & 83.8 & \\
\hline \multicolumn{5}{|l|}{ Model 2 (CEF) } \\
\hline Intercept & $4.50(0.81)$ & & & $<0.01$ \\
\hline \multicolumn{5}{|l|}{$\mathrm{Hp}(\mathrm{mg} / \mathrm{mL})$} \\
\hline$<0.78(\mathrm{n}=52)$ & $2.14(0.66)$ & $8.50(2.31-31.28)$ & 93.9 & $<0.01$ \\
\hline$>0.78(\mathrm{n}=116)$ & Referent & Baseline & 64.3 & \\
\hline \multicolumn{5}{|l|}{ DIM } \\
\hline$\leq 5(\mathrm{n}=30)$ & Referent & Baseline & 72.9 & $<0.01$ \\
\hline$>5(\mathrm{n}=138)$ & $1.34(0.50)$ & $3.80(1.41-10.27)$ & 91.1 & \\
\hline \multicolumn{5}{|l|}{ Dystocia } \\
\hline No $(\mathrm{n}=115)$ & Referent & Baseline & 76.3 & 0.07 \\
\hline Yes $(\mathrm{n}=53)$ & $0.98(0.53)$ & $2.66(0.94-7.59)$ & 89.5 & \\
\hline \multicolumn{5}{|c|}{ Vulvovaginal laceration } \\
\hline No $(\mathrm{n}=117)$ & $1.23(0.47)$ & $3.41(1.34-8.7)$ & 73.9 & 0.01 \\
\hline Yes $(\mathrm{n}=51)$ & Referent & Baseline & 90.6 & \\
\hline
\end{tabular}

${ }^{1}$ Cure was defined as absence of fetid watery vaginal discharge $12 \mathrm{~d}$ after enrollment.

${ }^{2} \mathrm{CON}=$ untreated controls; $\mathrm{CEF}=$ subcutaneous administration of $6.6 \mathrm{mg}$ of ceftiofur crystalline-free acid/ $\mathrm{kg}$ of $\mathrm{BW}$ administered at metritis diagnosis and $72 \mathrm{~h}$ later.

or death for each independent variable, Kaplan-Meier survival analysis was performed using MedCalc; the Logrank test was used to compute $P$-values. To evaluate the association between cow-related factors with milk production and rectal temperature, general linear models were fitted to the data using the MIXED procedure of SAS. The data comprised a series of repeated measures of each dependent variable at d $0,3,6,9$, and $12 \mathrm{~d}$ relative to enrollment for rectal temperature, and throughout the 10 mo of lactation for milk production. To account appropriately for within-cow correlation, the error term was modeled by imposing a first-order autoregressive covariance structure for all models. The interaction terms factor $\times$ time were forced into all models. The SLICE option was used to assess the mean differences by month of lactation using the TukeyKramer multicomparison adjustment method. Visual evaluation of the distribution plot of the studentized residuals was used to confirm that the residuals were normally distributed. For all models described above, statistical significance was declared if $P \leq 0.05$ and a tendency was considered if $0.10 \leq P>0.05$.

\section{RESULTS}

\section{Descriptive Statistics}

The descriptive statistics regarding number of animals enrolled, number of cows cured, parity, dystocia,

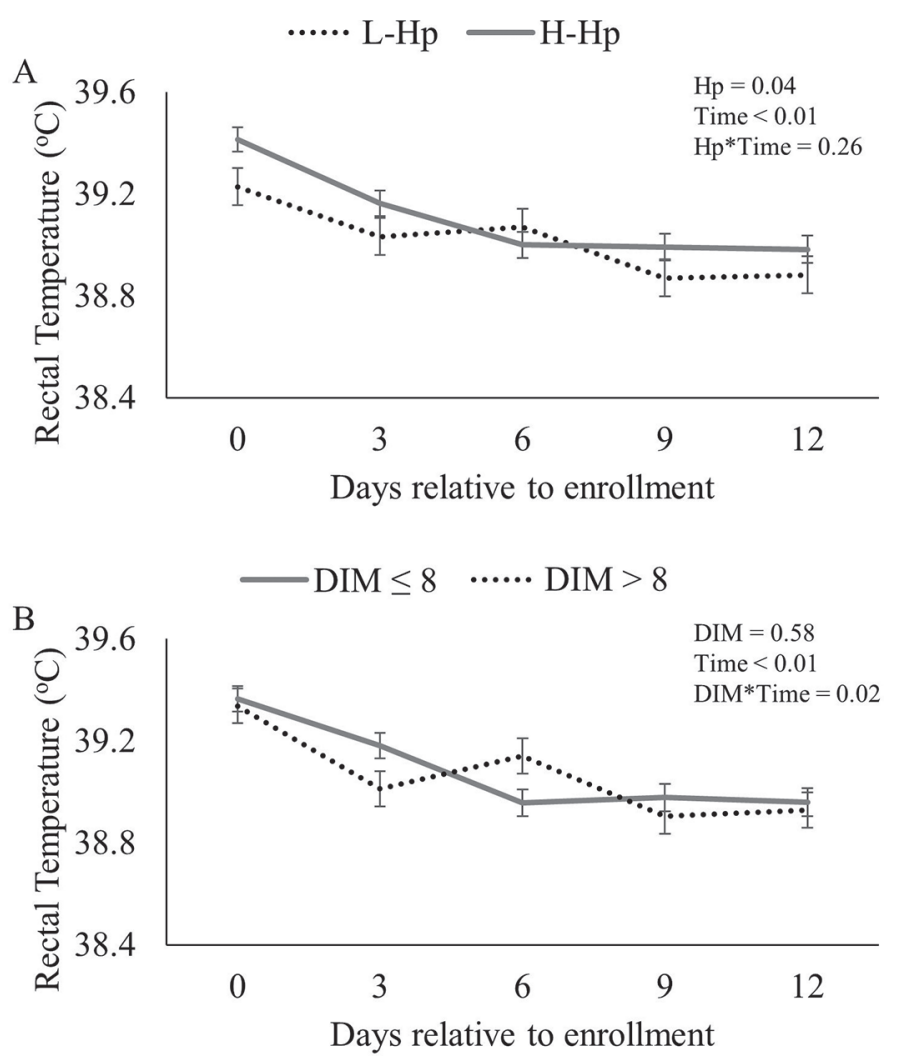

Figure 3. Least squares means of rectal temperature by days relative to metritis diagnosis for untreated metritic cows classified in $(\mathrm{A})$ H-Hp (high haptoglobin, $>0.54 \mathrm{mg} / \mathrm{mL}, \mathrm{n}=101$ ) and L-Hp (low haptoglobin, $\leq 0.54 \mathrm{mg} / \mathrm{mL}, \mathrm{n}=46$ ); and (B) DIM at metritis diagnosis $\leq 8(\mathrm{n}=96)$ and DIM $>8(\mathrm{n}=51)$. Error bars represent SEM. 
twin parturitions, RP, VL, average BCS at 5 DIM, average DIM and rectal temperature at enrollment, and average plasma concentration of NEFA, BHB, and $\mathrm{Hp}$ at enrollment for NMET cows, and metritic cows enrolled in CON and CEF groups are presented in Table 1. In the current study cohort, metritis cure was $64.6 \%$ and $81.5 \%$ for $\mathrm{CON}$ and $\mathrm{CEF}$ cows, respectively $(P$ $<0.01)$. Additionally, BCS was greater for CON and NMET cows than for CEF counterparts $(P<0.01)$. Cows enrolled in the CON group tended to have greater BHB plasma concentration at enrollment than CEF cows $(P=0.09)$. The incidence of dystocia, $\mathrm{RP}$, and VL was lower in NMET cows compared with CON and CEF cows $(P<0.01)$. Additionally, $8.2 \%(\mathrm{n}=12)$ and $3.6 \%(\mathrm{n}=6)$ of cows enrolled in the CON and CEF groups received escape therapy, respectively.

\section{Association of Cow-Related Factors with Metritis Cure}

The outcomes of the initial logistic regression models evaluating the association between several independent variables with metritis cure is presented in Table 2. Ceftiofur-treated cows were more likely to recover from metritis than untreated counterparts $(P<0.01)$. Additionally, plasma Hp $(P<0.01)$ DIM at metritis diagnosis $(P<0.01)$, VL $(P=0.08)$, and dystocia $(P=$ $0.08)$ were retained in the first logistic regression model.
Partition analysis revealed that the hierarchical order of variables predictive of metritis cure was plasma $\mathrm{Hp}$ concentration, DIM at metritis diagnosis, treatment, and dystocia (Figure 2). To further understand the variables associated with cure among $\mathrm{CON}$ and $\mathrm{CEF}$ cows, we stratified our analysis by treatment group. Among CON cows, DIM at metritis diagnosis was positively associated with metritis cure $(P=0.01)$, whereas plasma Hp concentration tended to be negatively associated with clinical cure $(P=0.10)$. Additionally, Hp $(P<0.01)$, DIM at metritis diagnosis $(P=0.05)$, dystocia $(P=0.06)$, and VL $(P<0.01)$ were retained in the model evaluating the association between several variables and metritis cure among CEF cows.

To facilitate interpretation of results, optimal threshold values for plasma Hp concentration and DIM at metritis diagnosis to predict metritis cure was determined for cows enrolled in CON and CEF groups (Table 3). Among CON cows, the $\mathrm{Hp}$ concentration threshold that maximized the AUC $(\mathrm{AUC}=0.64)$ was $\leq 0.54 \mathrm{mg} / \mathrm{mL}$, and the DIM cut point was $>8($ AUC $=$ 0.67). For CEF cows, the Hp concentration for metritis cure was $\leq 0.78 \mathrm{mg} / \mathrm{mL}(\mathrm{AUC}=0.76)$ and DIM cut point for metritis cure was $>5$ (0.67).

The final models evaluating the association between cow-related factors with the odds of cure of metritis for CON and CEF cows are presented in Table 4. Two-way interaction terms were not retained in the final models
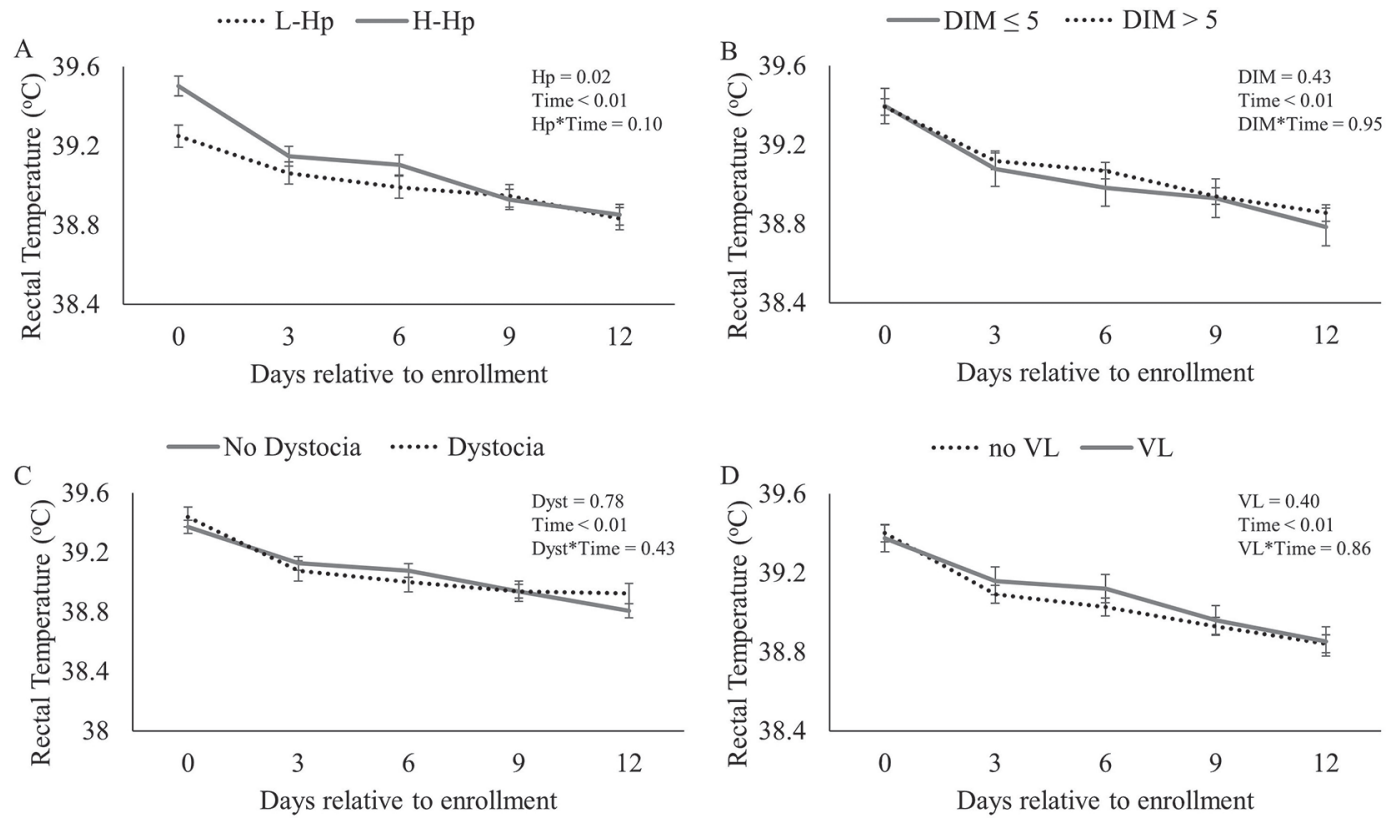

Figure 4. Least squares means of rectal temperature by days relative to metritis diagnosis for untreated metritic cows classified in (A) H-Hp (high haptoglobin, $>0.78 \mathrm{mg} / \mathrm{mL}, \mathrm{n}=116$ ) and L-Hp (low haptoglobin, $\leq 0.78 \mathrm{mg} / \mathrm{mL}, \mathrm{n}=52$ ); (B) DIM at metritis diagnosis $<5$ ( $\mathrm{n}=30$ ) and DIM $>5(\mathrm{n}=138) ;(\mathrm{C})$ dystocia (Dyst; $\mathrm{n}=53)$ and no dystocia $(\mathrm{n}=115)$; and $(\mathrm{D})$ vulvovaginal laceration $(\mathrm{VL}, \mathrm{n}=51)$ and $\mathrm{no}$ VL $(\mathrm{n}$ $=117)$. Error bars represent SEM. 
$(P>0.10)$. Among CON cows, cows with $\mathrm{Hp} \leq 0.54$ $\mathrm{mg} / \mathrm{mL}$ tended to have 2.22 higher odds of curing from metritis than cows with Hp concentration $>0.54 \mathrm{mg} /$ $\mathrm{mL}(P=0.09)$. Cows that developed metritis after 8 DIM were at 3.20 higher odds of being cured than cows that developed metritis at DIM $\leq 8(P=0.01)$. Among cows treated with ceftiofur, cows with plasma $\mathrm{Hp} \leq 0.78$ $\mathrm{mg} / \mathrm{mL}$ were at 8.50 increased odds of being cured from metritis than cows with Hp concentration $>0.78 \mathrm{mg} /$ $\mathrm{mL}(P<0.01)$. Furthermore, cows that were diagnosed with metritis after 5 DIM were 3.80 times more likely to be cured than cows that were diagnosed at DIM $\leq 5$ $(P<0.01)$. Cows that experienced dystocia tended to have 2.66 greater odds of recovering from metritis $(P=$ 0.07 ), whereas cows that did not have VL were at 3.41 higher odds of being cured $(P=0.01)$.

Rectal temperature was assessed at $0,3,6,9$, and $12 \mathrm{~d}$ relative to metritis diagnosis as a measure of disease severity. The dynamics of rectal temperature for untreated cows that had plasma $\mathrm{Hp}>0.54 \mathrm{mg} / \mathrm{mL}$ or $\leq 0.54 \mathrm{mg} / \mathrm{mL}$ and cows that were diagnosed with metritis at DIM $\leq 8$ or DIM $>8$ are illustrated in Figure 3. The rectal temperature changes for CEF cows that had plasma $\mathrm{Hp} \leq 0.78 \mathrm{mg} / \mathrm{mL}$ or $>0.78 \mathrm{mg} / \mathrm{mL}$, were diagnosed with metritis at DIM $\leq 5$ or DIM $>5$, had or did not have dystocia, and had or did not have VL are presented in Figure 4.

\section{Time to Conception}

The likelihood of conceiving for CON cows classified according to thresholds for $\mathrm{Hp}(>0.54 \mathrm{mg} / \mathrm{mL})$ and DIM $(\leq 8)$ for metritis diagnosis, and NMET cows is illustrated in Figure 5. In the CON group, cows with Hp $\leq 0.54 \mathrm{mg} / \mathrm{mL}$ tended to be 1.52 times more likely to conceive than cows with $\mathrm{Hp}>0.54 \mathrm{mg} / \mathrm{mL}(P=0.09)$. Additionally, the likelihood of conceiving was 1.78 times greater for NMET cows than cows with $\mathrm{Hp}>0.54 \mathrm{mg} /$ $\mathrm{mL}(P<0.01)$. The likelihood of conceiving was not different between NMET cows and cows with $\mathrm{Hp} \leq 0.54$ $\mathrm{mg} / \mathrm{mL}$. Furthermore, the likelihood of conceiving was not different between cows that were diagnosed with metritis after $8 \mathrm{DIM}$ or at DIM $\leq 8(P=0.20)$. Nonmetritic cows were 1.74 times more likely to become pregnant than cows that were diagnosed with metritis at DIM $\leq 8(P<0.01)$, but likelihood of conceiving was not different between NMET cows and cows that experienced metritis before 8 DIM $(P=0.24)$.

The likelihood of conceiving for CEF cows classified according to thresholds for $\mathrm{Hp}(>0.78 \mathrm{mg} / \mathrm{mL})$, DIM $(\leq 5)$ for metritis diagnosis, dystocia status, VL presence, and NMET cows is illustrated in Figure 6. Among CEF cows, the likelihood of pregnancy was not different between cows with $\mathrm{Hp}>0.78 \mathrm{mg} / \mathrm{mL}$ and cows with $\mathrm{Hp}$ $\leq 0.78 \mathrm{mg} / \mathrm{mL}(P=0.29)$. Nonmetritic cows tended to have greater likelihood to conceive than cows with $\mathrm{Hp}$ $>0.78 \mathrm{mg} / \mathrm{mL}(\mathrm{HR}=1.38, P=0.06)$, but pregnancy likelihood was not different between NMET cows and cows with $\mathrm{Hp} \leq 0.78 \mathrm{mg} / \mathrm{mL}(P=0.52)$. No differences in the likelihood of conceiving were found when comparing NMET cows with cows that were diagnosed
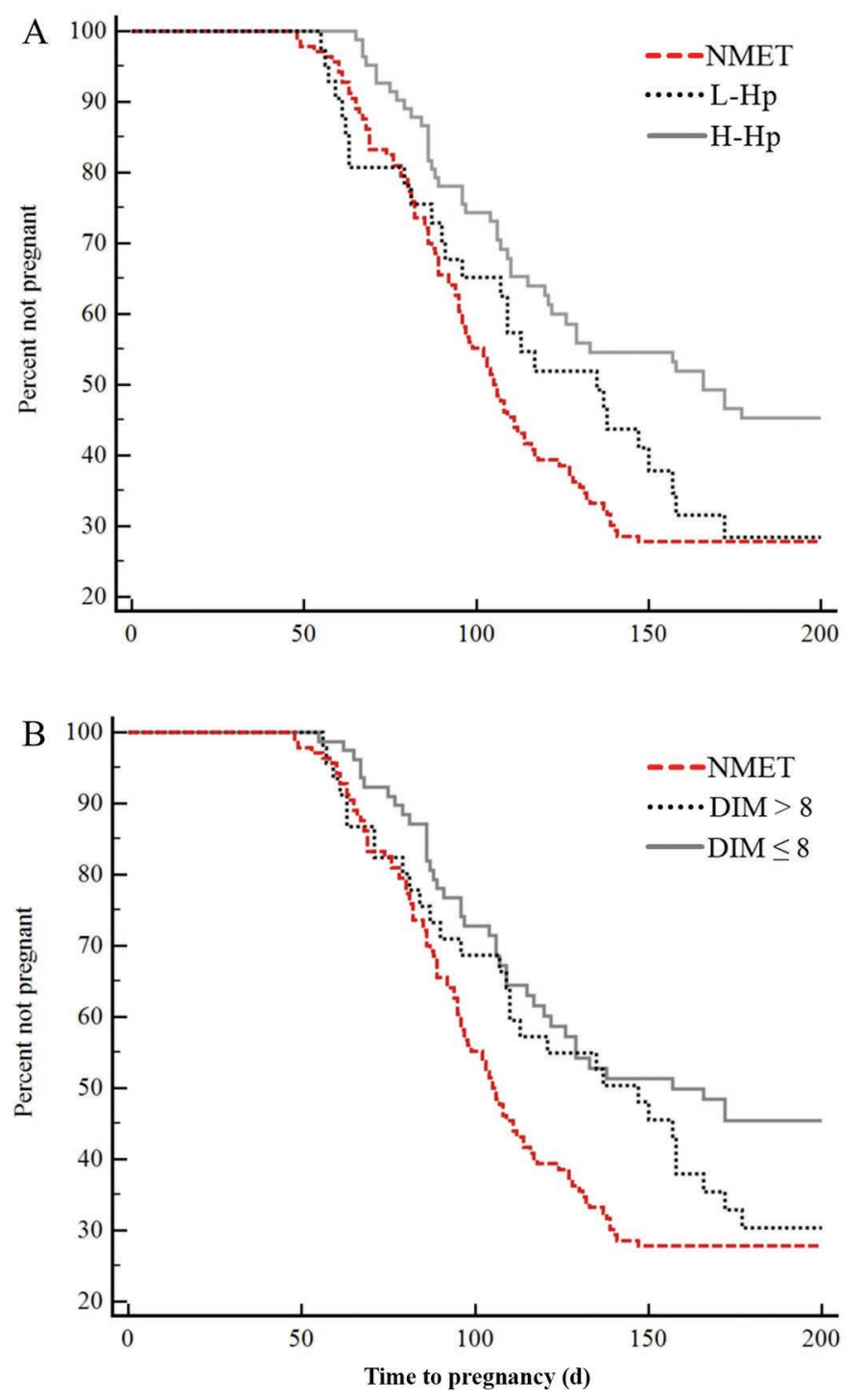

Figure 5. Kaplan-Meier survival analysis of calving to conception interval for untreated metritic cows classified in (A) H-Hp (high haptoglobin, $>0.54 \mathrm{mg} / \mathrm{mL}, \mathrm{n}=101$ ), L-Hp (low haptoglobin, $\leq 0.54$ $\mathrm{mg} / \mathrm{mL}, \mathrm{n}=46)$, and nonmetritic (NMET, $\mathrm{n}=150)$ cows; and $(\mathrm{B})$ $\mathrm{DIM} \leq 8(\mathrm{n}=96)$, DIM $>8(\mathrm{n}=51)$, and NMET $(\mathrm{n}=150)$ cows. The median calving to conception interval was 166, 135, and $105 \mathrm{~d}$ for H-Hp, L-Hp, and NMET cows, respectively $(P<0.01)$. Additionally, the median calving to conception interval for cows diagnosed with metritis at DIM $\leq 8$, DIM $>8$, and NMET cows was 157, 147, and 105, respectively $(P=0.01)$. 
with metritis after 5 DIM $(P=0.15)$ and at DIM $\leq 5$ $(P=0.29)$, and between cows that were diagnosed with metritis after 5 DIM and at DIM $\leq 5(P=0.80)$. Additionally, the likelihood of pregnancy was not influenced by dystocia status $(P=0.52)$, and no differences were observed between NMET cows and metritic cows that experienced dystocia $(P=0.13)$, and NMET cows and metritic cows that did not had a dystocic parturition $(P=0.23)$. Finally, presence of VL did not change the likelihood of pregnancy $(P=0.22)$, which also did not differ between NMET cows and cows with VL $(P=$ $0.11)$ and cows without VL $(P=0.27)$.

\section{Milk Production}

The least squares means of milk production for NMET cows $(39.8 \mathrm{~kg} / \mathrm{d})$, and CON cows with $\mathrm{Hp}>0.54 \mathrm{mg} / \mathrm{mL}$ $(37.7 \mathrm{~kg} / \mathrm{d}), \mathrm{Hp} \leq 0.54 \mathrm{mg} / \mathrm{mL}(38.9 \mathrm{~kg} / \mathrm{d})$, cows that developed metritis after 8 DIM $(37.4 \mathrm{~kg} / \mathrm{d})$, and cows that had metritis at DIM $\leq 8(39.4 \mathrm{~kg} / \mathrm{d})$ by month of lactation are presented in Figure 7. Metritic cows with $\mathrm{Hp}>0.54 \mathrm{mg} / \mathrm{mL}$ that were not treated with ceftiofur produced less milk than NMET cows during the first $(P<0.01)$ and second $(P=0.04)$ months of lactation, but no differences in milk production were observed between cows with $\mathrm{Hp} \leq 0.54 \mathrm{mg} / \mathrm{mL}$ and NMET cows. Additionally, NMET cows produced more milk than cows that were diagnosed with metritis before 8 DIM during the first 2 mo of lactation $(P<0.01)$, but milk production for cows diagnosed with metritis at DIM $>8$ and NMET cows was not different.

Figure 8 illustrates the least squares means of milk production during the first 10 mo of lactation for NMET cows $(39.9 \mathrm{~kg} / \mathrm{d})$, and CEF cows with $\mathrm{Hp}>0.78$ $\mathrm{mg} / \mathrm{mL}(39.1 \mathrm{~kg} / \mathrm{d})$ or $\leq 0.78 \mathrm{mg} / \mathrm{mL}(39.5 \mathrm{~kg} / \mathrm{d})$, DIM at metritis diagnosis $\leq 5(37.6 \mathrm{~kg} / \mathrm{mL})$ or after 5 DIM $(39.6 \mathrm{~kg} / \mathrm{d})$, had dystocia $(38.2 \mathrm{~kg} / \mathrm{d})$ or not $(39.9$ $\mathrm{kg} / \mathrm{d})$, and had VL $(38.2 \mathrm{~kg} / \mathrm{d})$ or not $(39.7 \mathrm{~kg} / \mathrm{d})$. The
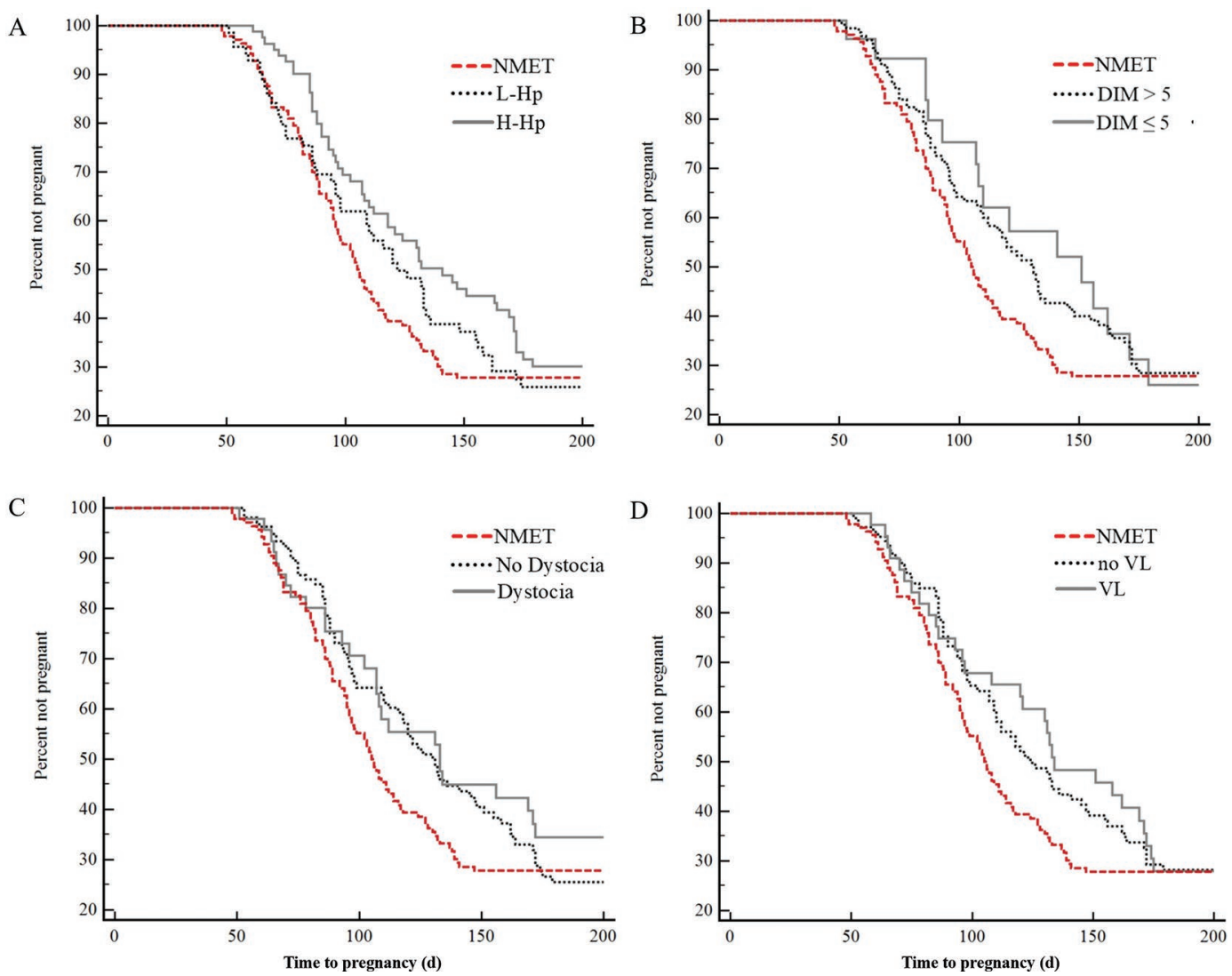

Figure 6. Kaplan-Meier survival analysis of calving to conception interval for metritic cows treated with ceftiofur and classified as (A) H-Hp (high haptoglobin, $>0.78 \mathrm{mg} / \mathrm{mL}, \mathrm{n}=116$ ), L-Hp (low haptoglobin, $\leq 0.78 \mathrm{mg} / \mathrm{mL}, \mathrm{n}=52$ ), and nonmetritic (NMET, $\mathrm{n}=150)$ cows; (B) DIM at metritis diagnosis $\leq 5(\mathrm{n}=30)$, DIM $>5(\mathrm{n}=138)$, and NMET cows $(\mathrm{n}=150) ;(\mathrm{C})$ dystocia $(\mathrm{n}=53)$, no dystocia $(\mathrm{n}=115)$, and NMET cows $(\mathrm{n}=150)$; and $(\mathrm{D})$ vulvovaginal laceration $(\mathrm{VL}, \mathrm{n}=51)$, no VL $(\mathrm{n}=117)$, and NMET $(\mathrm{n}=150)$ cows. The median calving to conception interval was 141, 122, and $105 \mathrm{~d}$ for $\mathrm{H}-\mathrm{Hp}$, L-Hp, and NMET cows, respectively $(P=0.19)$. Additionally, the median calving to conception interval for cows diagnosed with metritis at DIM $\leq 5$, DIM $>5$, and NMET cows was 151,131 , and 105 , respectively $(P=0.29)$. The median calving to conception interval was 130,133 , and $105 \mathrm{~d}$ for cows with dystocia, without dystocia, and NMET cows $(P=0.26)$. The median calving to conception interval for cows diagnosed with metritis with VL, without VL, and NMET cows was 134,124 , and 105 , respectively $(P=0.30)$. 
least squares means of milk production for NMET cows were $39.9 \mathrm{~kg} / \mathrm{d}$. Cows with $\mathrm{Hp}>0.78 \mathrm{mg} / \mathrm{mL}$ had lesser milk production in the first month of lactation compared with NMET counterparts $(P=0.02)$. No other differences in milk production were observed between NMET cows and CEF treated cows.

\section{Culling or Death}

The likelihood of culling or death of CON cows classified according to thresholds for $\mathrm{Hp}(>0.54 \mathrm{mg} / \mathrm{mL})$, DIM $(\leq 8)$ for metritis diagnosis, and NMET cows is illustrated in Figure 9. Among CON cows, the likelihood of culling or death was not different between cows with $\mathrm{Hp} \leq 0.54 \mathrm{mg} / \mathrm{mL}$ and cows with $\mathrm{Hp}>0.54 \mathrm{mg} / \mathrm{mL}$ $(P=0.94)$. However, in comparison to NMET counterparts, the likelihood of being culled/dead was 2.33 $(P=0.01)$ and $2.18(P=0.06)$ times greater for cows with $\mathrm{Hp}>0.54 \mathrm{mg} / \mathrm{mL}$ and cows with $\mathrm{Hp} \leq 0.54 \mathrm{mg} /$ $\mathrm{mL}$, respectively. Additionally, the likelihood of culling or death was not different between cows diagnosed with metritis at DIM $\leq 8$ or after 8 DIM $(P=0.21)$. In comparison to NMET counterparts, the hazard of culling or death was 2.74 greater for cows diagnosed with metritis at DIM $\leq 8(P<0.01)$. Cows diagnosed with metritis after 8 DIM were not more likely to be culled or dead than NMET ones $(P=0.32)$.

The likelihood of being culled or dead for CEF cows classified according to threshold for $\mathrm{Hp}(>0.78 \mathrm{mg} /$ $\mathrm{mL})$, DIM $(\leq 5)$ for metritis diagnosis, dystocia status, VL presence, and NMET cows is illustrated in Figure 10. Among ceftiofur-treated cows, cows with $\mathrm{Hp}$ $>0.78 \mathrm{mg} / \mathrm{mL}$ tended to be 2.13 times more likely to be culled/dead than cows with $\mathrm{Hp} \leq 0.78 \mathrm{mg} / \mathrm{mL}(P=$ 0.09). The likelihood of culling or death was 2.07 times greater for cows with $\mathrm{Hp}>0.78 \mathrm{mg} / \mathrm{mL}$ compared with NMET counterparts $(P=0.03)$, but it did not differ between cows with $\mathrm{Hp} \leq 0.78 \mathrm{mg} / \mathrm{mL}$ and NMET cows $(P=0.95)$. The likelihood of culling or death for cows diagnosed with metritis at DIM $\leq 5$ was 2.39 and 3.06 greater than for cows diagnosed with metritis before 5 DIM $(P=0.04)$ or NMET counterparts $(P=0.01)$, respectively. The likelihood of culling or death did not differ between cows diagnosed with metritis at 5 DIM and NMET cows $(P=0.48)$. Furthermore, dystocia did not change the likelihood of being culled or dead among cows that were treated for metritis $(P=0.11)$, but compared with NMET cows, cows that had dystocia had 2.34 times greater likelihood of being culled or dead $(P=0.03)$. Finally, among cows diagnosed with metritis, VL did not influence the likelihood of culling or death $(P=0.14)$, but cows with VL were 2.53 times more likely to be culled or dead than NMET cows $(P$ $=0.03)$.

\section{DISCUSSION}

The current study used data from a clinical trial designed to evaluate the intrauterine infusion of $\mathrm{CM}$ as an alternative therapy for metritis in dairy cows (Oliveira et al., 2020). In addition to the chitosan treatment group, cows were also enrolled in a positive control $(\mathrm{CEF})$ and negative control $(\mathrm{CON})$. Oliveira et al. (2020) reported that the proportion of cows cured from metritis $12 \mathrm{~d}$ after diagnosis was $61.9 \%$ and $77.9 \%$ for CON and CEF cows. In the subset of cows used in our study, metritis cure for CON and CEF cows was $64.6 \%$ to $81.5 \%$, which was consistent with others that reported that CEF was an efficacious therapy for metritis in dairy cows (Chenault et al., 2004; McLaughlin et al., 2012). Also similar to previous work from Chenault et al. (2004) and McLaughlin et al. (2012), spontaneous cure occurred in more than half of our cows and treatment failure occurred in almost $20 \%$ of treated metritis cases.

The number needed to treat, defined as $100 \%$ divided by the difference in cure attributable to therapy, is a

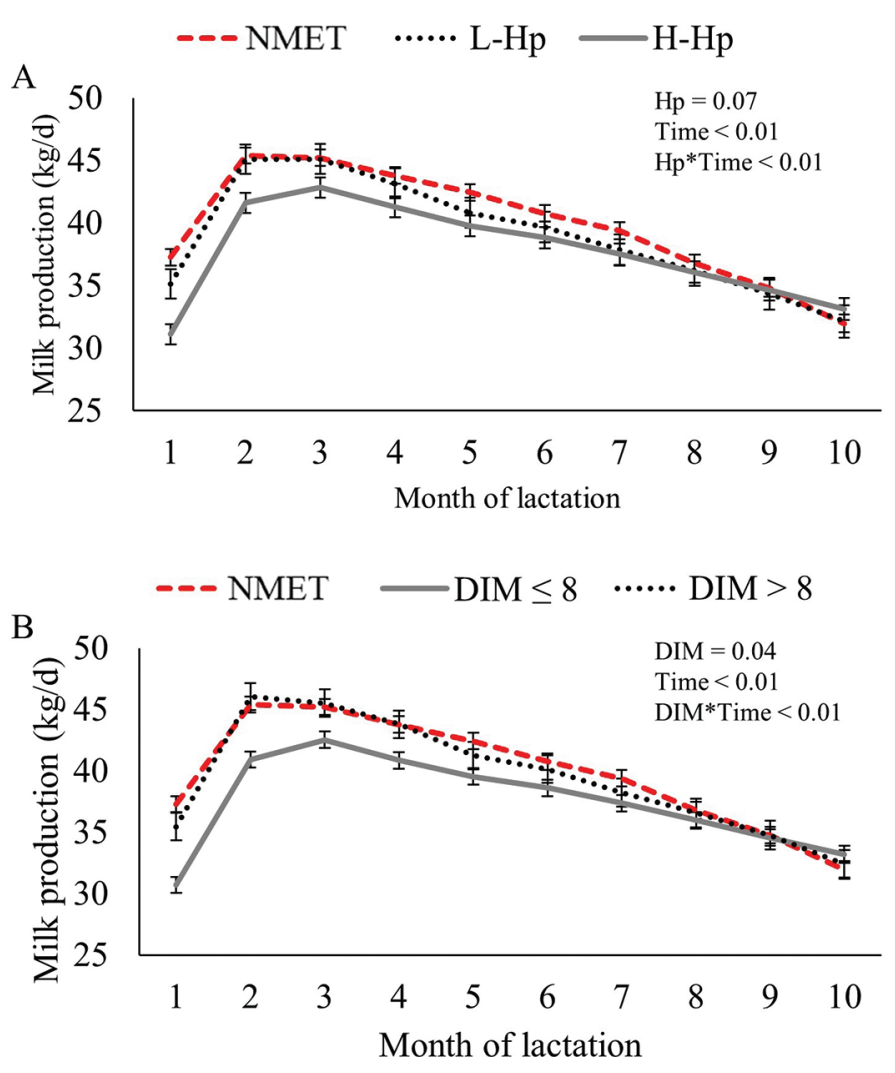

Figure 7. Least squares means milk production by month of lactation for untreated metritic cows classified in (A) H-Hp (high haptoglobin, $>0.54 \mathrm{mg} / \mathrm{mL}, \mathrm{n}=100$ ), L-Hp (low haptoglobin, $\leq 0.54 \mathrm{mg} /$ $\mathrm{mL}, \mathrm{n}=46$ ), and nonmetritic (NMET, $\mathrm{n}=150$ ) cows; and (B) DIM at metritis diagnosis $\leq 8(\mathrm{n}=95)$, DIM $>8(\mathrm{n}=51)$, and NMET $(\mathrm{n}=$ 150) cows. Error bars represent SEM. 
useful statistic that indicates how many animals need to be treated to change the cure outcome of one animal (Cook and Sackett, 1995). In our study, the number needed to treat was 5.9 , which means that we needed to treat approximately 6 cows to change the cure outcome of 1 . This finding highlights the importance of better understanding factors associated with metritis cure and develop targeted therapy strategies. However, it is important to emphasize that the current recommendation of metritis therapy with CEF can improve milk yield in the first $60 \mathrm{~d}$ of lactation (Oliveira et al., 2020) and shorten the calving to conception of dairy cows (Giuliodori et al., 2013; Piccardi et al., 2016; Oliveira et al., 2020). Hence, in addition to clinical cure, economically important outcomes such as reproductive performance, culling, and milk yield were considered in our analysis. A logistic regression model revealed that, overall, treatment, $\mathrm{Hp}$, and DIM at metritis diagnosis were associated with cure, and VL and dystocia tended to be associated with cure. In a partition analysis, it was determined that $\mathrm{Hp}$ and DIM at diagnosis were more predictive of cure than treatment, highlighting the need to establish which cow-related factors can lead to the development of a selective strategy for metritis therapy.

Previously, it was observed that parity was associated with early cure of metritis (evaluated within the first week after initial diagnosis) when metritis was treated either with CEF or ampicillin (Lima et al., 2014). However, Lima et al. (2014) reported that parity
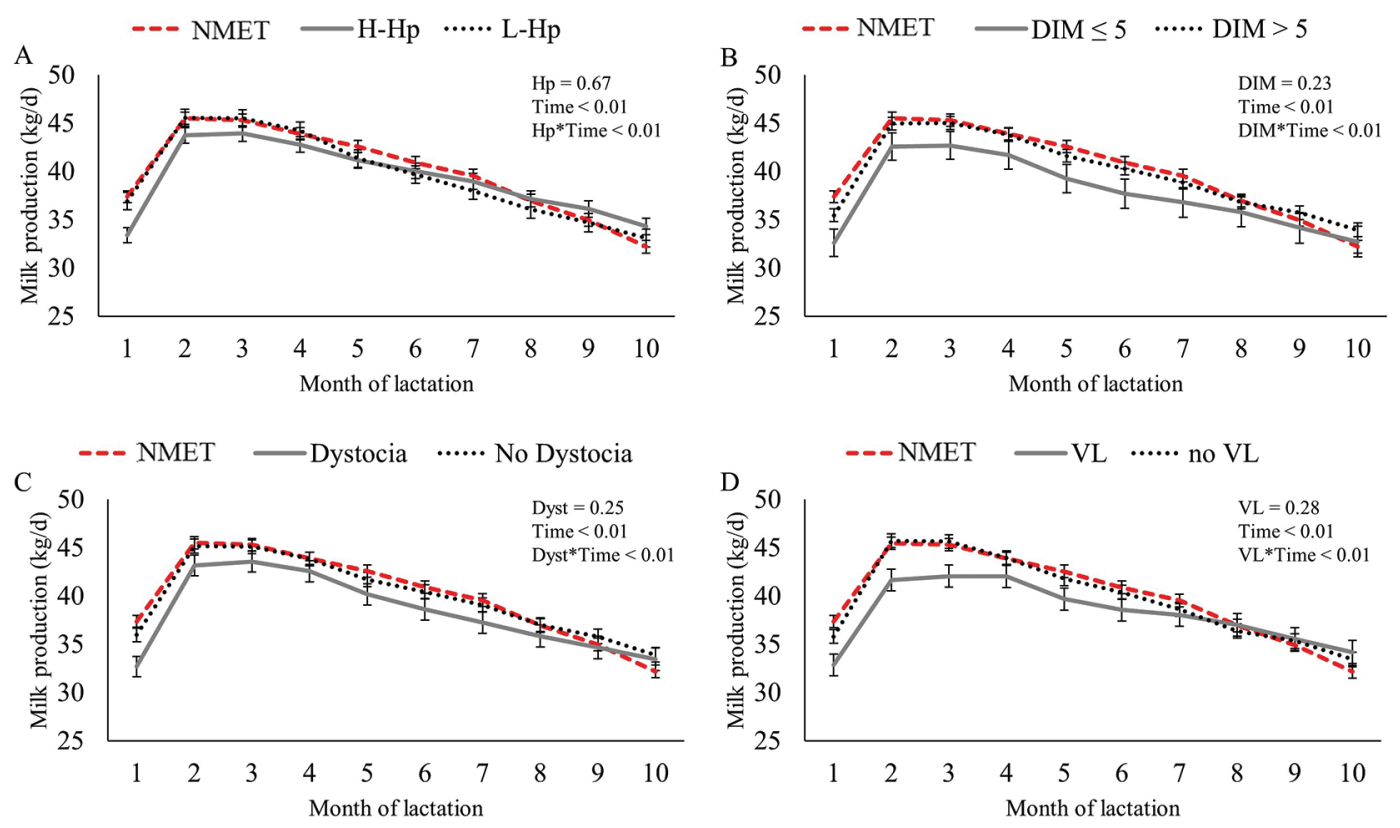

Figure 8. Least squares means milk production by month of lactation for untreated metritic cows classified in (A) H-Hp (high haptoglobin, $>0.78 \mathrm{mg} / \mathrm{mL}, \mathrm{n}=116$ ), L-Hp (low haptoglobin, $\leq 0.78 \mathrm{mg} / \mathrm{mL}, \mathrm{n}=52$ ), and nonmetritic (NMET, $\mathrm{n}=150)$ cows; (B) DIM at metritis diagnosis $\leq 5(\mathrm{n}=30)$, DIM $>5(\mathrm{n}=138)$, and NMET cows $(\mathrm{n}=150) ;(\mathrm{C})$ dystocia (Dyst; $\mathrm{n}=53)$, no dystocia $(\mathrm{n}=115)$, and NMET cows $(\mathrm{n}=150)$; and $(\mathrm{D})$ vulvovaginal laceration $(\mathrm{VL}, \mathrm{n}=51)$, no VL $(\mathrm{n}=117)$, and NMET $(\mathrm{n}=150)$ cows. Error bars represent SEM. 
milk yield, and greater culling, in comparison to NMET cows. This is not surprising as calving-related problems have been previously associated with decreased milk yield, longer calving to conception intervals, and affected culling decisions in dairy farms (Tenhagen et al., 2007; Gaafar et al., 2011; Vieira-Neto et al., 2016).

Results from a pilot study suggested that leaving metritis cases that occurred within the first 5 DIM did not lead to negative outcomes (Sannmann et al., 2013). However, our data are in contrast with this recommendation, suggesting that cows that develop metritis earlier in lactation are less likely to recover. Among CEF cows, metritis cases that occurred within the first 5 DIM were also less likely to cure, and when untreated, metritis cases were more likely to cure if occurred after 8 DIM. Our data also show that when untreated, metritis cases that occurred after 8 DIM were not associated with milk yield, reproductive performance, and culling losses in comparison to NMET counterparts. It is important to highlight that due to time constraints in the field, we were not able to monitor metritis for all cows within 21 DIM. We adopted a strategy that would allow us to detect most metritis cases, based on the incidence peak of the disease. We systemically examined cows at 5, 7, and 9 DIM. In addition, cows identified by farm employees as potential metritis cases based on systemic signs of illness (inappetence, dullness, milk deviation detected in the parlor) were also examined by the research team. Hence, cows enrolled in the study in DIM other than 5, 7, and 9 could potentially be suffering from more severe cases of metritis. Hence, our results regarding DIM at metritis diagnosis should be interpreted with care. For example, it is possible that the reason why cows diagnosed with metritis within the first 5 DIM were less likely to recover from metritis after ceftiofur treatment might be due to the fact that many of those metritis cases might have been severe, and timing of disease development does not necessarily lead to treatment failure.

Haptoglobin is an acute phase protein that has been consistently associated with metritis incidence in dairy cows (Galvão et al., 2010; Bicalho et al., 2014; Barragan et al., 2018). Circulating concentrations of $\mathrm{Hp}$ as a tool for the diagnosis and prediction of metritis has been previously evaluated (Burfeind et al., 2014; Pohl et al., 2015). Additionally, Hp concentration was associated with metritis severity (based on vaginal discharge appearance and rectal temperature), with cows diagnosed with severe cases of metritis having greater circulating $\mathrm{Hp}$ concentration than cows diagnosed with mild metritis (Huzzey et al., 2009). Herein, we observed that high plasma concentration of $\mathrm{Hp}(>0.78$ $\mathrm{mg} / \mathrm{mL}$ ) assessed at metritis diagnosis was associated with treatment failure, and that low circulating concen- tration of $\mathrm{Hp}(\leq 0.54 \mathrm{mg} / \mathrm{mL})$ tended to be associated with spontaneous cure. However, based on the ROC curve analysis outcomes, the accuracy of circulating $\mathrm{Hp}$ to predict cure among $\mathrm{CON}$ and $\mathrm{CEF}$ cows was at best moderate (Greiner et al., 2000). Pohl et al. (2015) speculated that $\mathrm{Hp}$ is not an accurate tool to detect metritis because its concentration is also elevated when cows suffer from other conditions such as dystocia, RP, and metabolic imbalance.

Although the accuracy of $\mathrm{Hp}$ to predict cure was only moderate, milk production analysis revealed that $\mathrm{Hp}$ could be useful to predict metritis cases that will lead
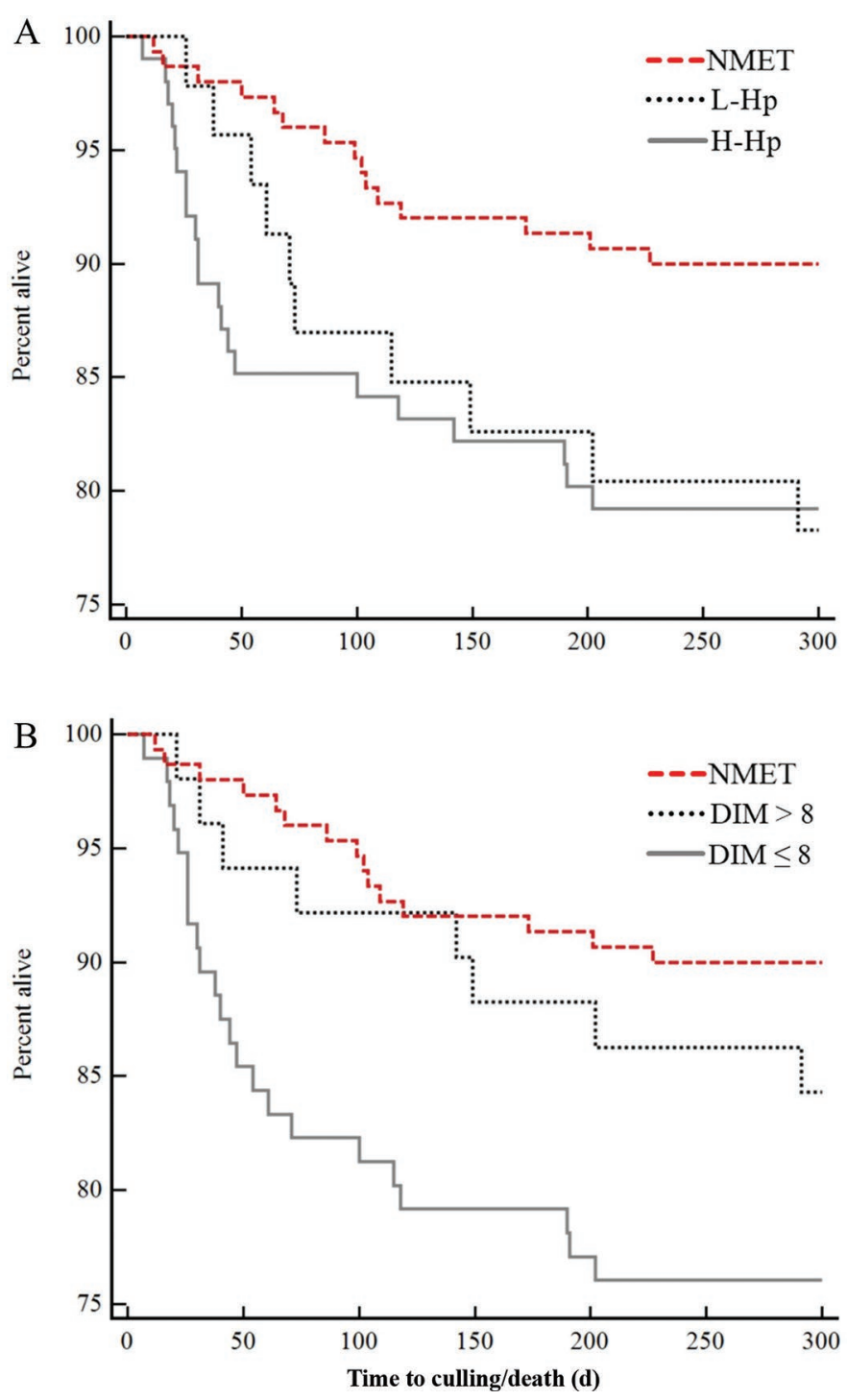

Figure 9. Kaplan-Meier survival analysis of probability of culling or death for untreated metritic cows classified in (A) H-Hp (high haptoglobin, $>0.54 \mathrm{mg} / \mathrm{mL}, \mathrm{n}=101$ ), L-Hp (low haptoglobin, $\leq 0.54$ $\mathrm{mg} / \mathrm{mL}, \mathrm{n}=46)$, and nonmetritic (NMET, $\mathrm{n}=150)$ cows $(P=0.03)$; and $(B)$ DIM $\leq 8(\mathrm{n}=96)$, DIM $>8(\mathrm{n}=51)$, and NMET $(\mathrm{n}=150)$ cows $(P<0.01)$. 
to milk yield losses, poor reproductive outcomes, and increased culling. We observed that $\mathrm{CON}$ cows with $\mathrm{Hp}$ $\leq 0.54 \mathrm{mg} / \mathrm{mL}$ and CEF cows with $\mathrm{Hp} \leq 0.78 \mathrm{mg} / \mathrm{mL}$ had similar milk production, reproductive performance, and culling risk when compared with NMET cows. Others have reported that high circulating concentration of $\mathrm{Hp}$ can be indicative of low performance. For instance, clinically healthy cows with high concentrations of $\mathrm{Hp}$ in blood during the first week of lactation had increased calving to conception intervals than cows with low Hp (Nightingale et al., 2015). Additionally, metritic cases associated with milk losses were also associated with greater circulating concentration of $\mathrm{Hp}$ at 3 and 7 DIM (Stangaferro et al., 2016). It is important to highlight that metritic cows were more likely to leave the herd than NMET counterparts. Hence, it is possible that the magnitude in the differences observed in milk production and reproductive performance could have been larger if culled cows were retained in the herd throughout the study period. However, the available data on monthly milk yields and calving to conception interval from culled cows (both metritic and NMET cows) contributed to the statistical models used herein.

Collectively, our findings indicate that the development of a selective therapy for metritis using cow-related factors is a possibility. For instance, we can speculate that cows that develop metritis after 8 DIM or have plasma Hp concentration $\leq 0.54 \mathrm{mg} / \mathrm{mL}$ at metritis diagnosis could be left untreated without major economic impacts. Additionally, we speculate that nonsteroidal antiinflammatory drugs could be indicated as an ancillary therapy for metritis for cows that have circulating $\mathrm{Hp}$ concentration $>0.78 \mathrm{mg} / \mathrm{mL}$ (Laven et al., 2012). For instance, sodium salicylate treatment in early lactation increased milk production of dairy cows, and it could be more beneficial to cows in greater inflammatory states (Farney et al., 2013). However, it is important to highlight that when meloxicam was administered to all metritis cases, it did not improve feeding and social behaviors of cows (Lomb et al., 2018), and when flunixin meglumine was used as an adjunct therapy for metritis, milk yield and repro-
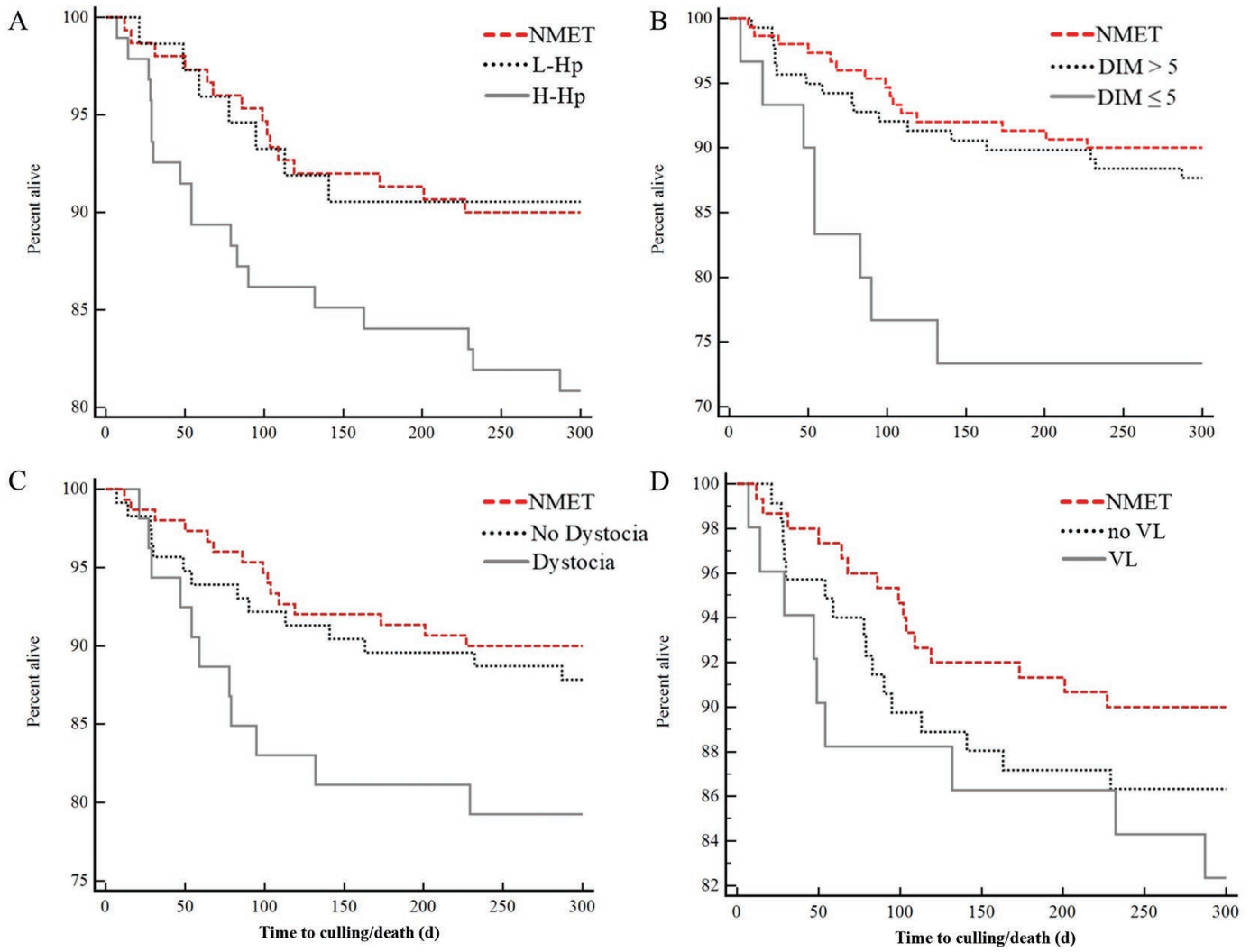

Figure 10. Kaplan-Meier survival analysis of probability of culling or death for metritic cows treated with ceftiofur and classified as (A) H-Hp (high haptoglobin, $>0.78 \mathrm{mg} / \mathrm{mL}, \mathrm{n}=116$ ), L-Hp (low haptoglobin, $\leq 0.78 \mathrm{mg} / \mathrm{mL}, \mathrm{n}=52$ ), and nonmetritic (NMET, $\mathrm{n}=150$ ) cows $(P=0.06)$; (B) DIM at metritis diagnosis $\leq 5(\mathrm{n}=30)$, DIM $>5(\mathrm{n}=138)$, and NMET $(\mathrm{n}=150)$ cows $(P=0.03) ;(\mathrm{C})$ dystocia $(\mathrm{n}=53)$, no dystocia $(\mathrm{n}=115)$, and NMET $(\mathrm{n}=150) \operatorname{cows}(P=0.11)$; and $(\mathrm{D})$ vulvovaginal laceration $(\mathrm{VL}, \mathrm{n}=51)$, no VL $(\mathrm{n}=117)$, and NMET $(\mathrm{n}=$ 150) cows $(P=0.30)$. 
ductive outcomes were not improved (Drillich et al., 2007). However, more research is needed to design and evaluate the feasibility and economic impact of selective therapy for metritis. It is important to highlight that this study was conducted in only one herd, and that other variables that were not considered here could be more accurate predictors of metritis cure. Additionally, it is possible that multiple variables should be used in an algorithm to guide treatment decision trees, similarly to what has been proposed for selective dry-cow therapy (Vasquez et al., 2018) and diarrhea in calves (Gomez et al., 2017).

\section{CONCLUSIONS}

We observed that among CON cows, circulating concentration of $\mathrm{Hp}$ and DIM at metritis diagnosis are associated with risk of cure for metritis. In addition, plasma Hp, DIM at metritis diagnosis, VL, and dystocia influence the risk of cure for CEF cows. In general, the accuracy of those variables to predict metritis cure was only moderate. Hence, for the development of a selective therapy strategy for metritis, more research is needed to identify more accurate predictors of metritis spontaneous cure and treatment failure.

\section{ACKNOWLEDGMENTS}

The results presented in this manuscript were generated with support of 2 grants from the USDA-National Institute of Food and Agriculture (NIFA)-Agriculture and Food Research Initiative (AFRI; Kansas City, MO) program (grant numbers: 2016-67015-25015 and 2019-67015-29865). The authors have not stated any conflicts of interest.

\section{REFERENCES}

Barragan, A. A., J. M. Piñeiro, G. M. Schuenemann, P. J. RajalaSchultz, D. E. Sanders, J. Lakritz, and S. Bas. 2018. Assessment of daily activity patterns and biomarkers of pain, inflammation, and stress in lactating dairy cows diagnosed with clinical metritis. J. Dairy Sci. 101:8248-8258. https://doi.org/10.3168/jds.2018-14510.

Bicalho, M. L., V. S. Machado, G. Oikonomou, R. O. Gilbert, and R. C. Bicalho. 2012. Association between virulence factors of Escherichia coli, Fusobacterium necrophorum, and Arcanobacterium pyogenes and uterine diseases of dairy cows. Vet. Microbiol. 157:125-131. https://doi.org/10.1016/j.vetmic.2011.11.034.

Bicalho, M. L. S., F. S. Lima, E. K. Ganda, C. Foditsch, E. B. S. Meira Jr., V. S. Machado, A. G. V. Teixeira, G. Oikonomou, R. O. Gilbert, and R. C. Bicalho. 2014. Effect of trace mineral supplementation on selected minerals, energy metabolites, oxidative stress, and immune parameters and its association with uterine diseases in dairy cattle. J. Dairy Sci. 97:4281-4295. https://doi.org/10.3168/ jds.2013-7832.

Burfeind, O., M. Bruins, A. Bos, I. Sannmann, R. Voigtsberger, and W. Heuwieser. 2014. Diagnosis of acute puerperal metritis by electronic nose device analysis of vaginal discharge in dairy cows. The- riogenology 82:64-70. https://doi.org/10.1016/j.theriogenology .2014.03.001.

Chenault, J. R., J. F. McAllister, S. T. Chester Jr., K. J. Dame, F. M. Kausche, and E. J. Robb. 2004. Efficacy of ceftiofur hydrochloride sterile suspension administered parenterally for the treatment of acute postpartum metritis in dairy cows. J. Am. Vet. Med. Assoc. 224:1634-1639. https://doi.org/10.2460/javma.2004.224.1634.

Cook, R. J., and D. L. Sackett. 1995. The number needed to treat: A clinically useful measure of treatment effect. BMJ 310:452-454. https://doi.org/10.1136/bmj.310.6977.452.

Cooke, R. F., and J. D. Arthington. 2013. Concentrations of haptoglobin in bovine plasma determined by ELISA or a colorimetric method based on peroxidase activity. J. Anim. Physiol. Anim. Nutr. (Berl.) 97:531-536. https://doi.org/10.1111/j.1439-0396 .2012.01298.x.

Dolejska, M., Z. Jurcickova, I. Literak, L. Pokludova, J. Bures, A. Hera, L. Kohoutova, J. Smola, and A. Cizek. 2011. IncN plasmids carrying bla CTX-M-1 in Escherichia coli isolates on a dairy farm. Vet. Microbiol. 149:513-516. https://doi.org/10.1016/j.vetmic .2010.11.032.

Drillich, M., D. Voigt, D. Forderung, and W. Heuwieser. 2007. Treatment of acute puerperal metritis with flunixin meglumine in addition to antibiotic treatment. J. Dairy Sci. 90:3758-3763. https:// doi.org/10.3168/jds.2007-0052.

Dubuc, J., T. F. Duffield, K. E. Leslie, J. S. Walton, and S. J. LeBlanc. 2010. Risk factors for postpartum uterine diseases in dairy cows. J. Dairy Sci. 93:5764-5771. https://doi.org/10.3168/jds.2010-3429.

Edmonson, A. J., I. J. Lean, L. D. Weaver, T. Farver, and G. Webster. 1989. A body condition scoring chart for Holstein dairy cows. J. Dairy Sci. 72:68-78. https://doi.org/10.3168/jds.S0022 -0302(89)79081-0.

Espadamala, A., R. Pereira, P. Pallarés, A. Lago, and N. Silva-delRío. 2018. Metritis diagnosis and treatment practices in 45 dairy farms in California. J. Dairy Sci. 101:9608-9616. https://doi.org/ $10.3168 /$ jds.2017-14296.

Farney, J. K., L. K. Mamedova, J. F. Coetzee, J. E. Minton, L. C. Hollis, and B. J. Bradford. 2013. Sodium salicylate treatment in early lactation increases whole-lactation milk and milk fat yield in mature dairy cows. J. Dairy Sci. 96:7709-7718. https://doi.org/10 $.3168 /$ jds.2013-7088.

Gaafar, H. M. A., S. M. Shamiah, M. A. A. El-Hamd, A. A. Shitta, and M. A. T. El-Din. 2011. Dystocia in Friesian cows and its effects on postpartum reproductive performance and milk production. Trop. Anim. Health Prod. 43:229-234. https://doi.org/10 $.1007 / \mathrm{s} 11250-010-9682-3$.

Galvão, K. N., M. J. Flaminio, S. B. Brittin, R. Sper, M. Fraga, L. Caixeta, A. Ricci, C. L. Guard, W. R. Butler, and R. O. Gilbert. 2010. Association between uterine disease and indicators of neutrophil and systemic energy status in lactating Holstein cows. J. Dairy Sci. 93:2926-2937. https://doi.org/10.3168/jds.2009-2551.

Giuliodori, M. J., R. P. Magnasco, D. Becu-Villalobos, I. M. LacauMengido, C. A. Risco, and R. L. de la Sota. 2013. Metritis in dairy cows: risk factors and reproductive performance. J. Dairy Sci. 96:3621-3631. https://doi.org/10.3168/jds.2012-5922.

Gomez, D. E., L. G. Arroyo, Z. Poljak, L. Viel, and J. S. Weese. 2017. Implementation of an algorithm for selection of antimicrobial therapy for diarrhoeic calves: Impact on antimicrobial treatment rates, health and faecal microbiota. Vet. J. 226:15-25. https://doi .org/10.1016/j.tvjl.2017.06.009.

Greiner, M., D. Pfeiffer, and R. D. Smith. 2000. Principles and practical application of the receiver-operating characteristic analysis for diagnostic tests. Prev. Vet. Med. 45:23-41. https://doi.org/10 .1016/S0167-5877(00)00115-X.

Haimerl, P., and W. Heuwieser. 2014. Invited review: Antibiotic treatment of metritis in dairy cows: A systematic approach. J. Dairy Sci. 97:6649-6661. https://doi.org/10.3168/jds.2014-8462.

Hammon, D. S., I. M. Evjen, T. R. Dhiman, J. P. Goff, and J. L. Walters. 2006. Neutrophil function and energy status in Holstein cows with uterine health disorders. Vet. Immunol. Immunopathol. 113:21-29. https://doi.org/10.1016/j.vetimm.2006.03.022. 
Huzzey, J. M., T. F. Duffield, S. J. LeBlanc, D. M. Veira, D. M. Weary, and M. A. G. von Keyserlingk. 2009. Short communication: Haptoglobin as an early indicator of metritis. J. Dairy Sci. 92:621-625. https://doi.org/10.3168/jds.2008-1526.

Jeon, S. J., F. Cunha, X. Ma, N. Martinez, A. Vieira-Neto, R. Daetz, R. C. Bicalho, S. Lima, J. E. P. Santos, K. C. Jeong, and K. N. Galvão. 2016. Uterine microbiota and immune parameters associated with fever in dairy cows with metritis. PLoS One 11:e0165740. https://doi.org/10.1371/journal.pone.0165740.

Jeon, S. J., A. Vieira-Neto, M. Gobikrushanth, R. Daetz, R. D. Mingoti, A. C. B. Parize, S. L. de Freitas, A. N. L. da Costa, R. C. Bicalho, S. Lima, K. C. Jeong, and K. N. Galvão. 2015. Uterine microbiota progression from calving until establishment of metritis in dairy cows. Appl. Environ. Microbiol. 81:6324-6332. https://doi .org/10.1128/AEM.01753-15.

Kass, G. V. 1980. An exploratory technique for investigating large quantities of categorical data. Appl. Stat. 29:119. https://doi.org/ $10.2307 / 2986296$.

Laven, R., P. Chambers, and K. Stafford. 2012. Using non-steroidal anti-inflammatory drugs around calving: Maximizing comfort, productivity and fertility. Vet. J. 192:8-12. https://doi.org/10 $.1016 /$ j.tvjl.2011.10.023.

LeBlanc, S. J., T. Osawa, and J. Dubuc. 2011. Reproductive tract defense and disease in postpartum dairy cows. Theriogenology 76:1610-1618. https://doi.org/10.1016/j.theriogenology.2011.07 .017 .

Lima, F. S., A. Vieira-Neto, J. A. Snodgrass, A. De Vries, and J. E. P. Santos. 2019. Economic comparison of systemic antimicrobial therapies for metritis in dairy cows. J. Dairy Sci. 102:7345-7358. https://doi.org/10.3168/jds.2018-15383.

Lima, F. S., A. Vieira-Neto, G. S. Vasconcellos, R. D. Mingoti, E. Karakaya, E. Sole, R. S. Bisinotto, N. Martinez, C. A. Risco, K. N. Galvao, and J. E. Santos. 2014. Efficacy of ampicillin trihydrate or ceftiofur hydrochloride for treatment of metritis and subsequent fertility in dairy cows. J. Dairy Sci. 97:5401-5414. https://doi.org/ 10.3168/jds.2013-7569.

Lomb, J., H. W. Neave, D. M. Weary, S. J. LeBlanc, J. M. Huzzey, and M. A. G. von Keyserlingk. 2018. Changes in feeding, social, and lying behaviors in dairy cows with metritis following treatment with a nonsteroidal anti-inflammatory drug as adjunctive treatment to an antimicrobial. J. Dairy Sci. 101:4400-4411. https://doi.org/10 $.3168 /$ jds.2017-13812.

Makimura, S., and N. Suzuki. 1982. Quantitative determination of bovine serum haptoglobin and its elevation in some inflammatory diseases. Nippon Juigaku Zasshi 44:15-21. https://doi.org/10 $.1292 /$ jvms1939.44.15.

McLaughlin, C. L., E. Stanisiewski, M. J. Lucas, C. P. Cornell, J. Watkins, L. Bryson, J. K. Tena, J. Hallberg, and J. R. Chenault. 2012. Evaluation of two doses of ceftiofur crystalline free acid sterile suspension for treatment of metritis in lactating dairy cows. J. Dairy Sci. 95:4363-4371. https://doi.org/10.3168/jds.2011-5111.

McLaughlin, C. L., E. P. Stanisiewski, C. A. Risco, J. E. P. Santos, G. E. Dahl, R. C. Chebel, C. LaGrow, C. Daugherty, L. Bryson, D. Weigel, J. Hallberg, and M. J. Lucas. 2013. Evaluation of ceftiofur crystalline free acid sterile suspension for control of metritis in high-risk lactating dairy cows. Theriogenology 79:725-734. https:/ /doi.org/10.1016/j.theriogenology.2012.11.029.

Nightingale, C. R., M. D. Sellers, and M. A. Ballou. 2015. Elevated plasma haptoglobin concentrations following parturition are associated with elevated leukocyte responses and decreased subsequent reproductive efficiency in multiparous Holstein dairy cows. Vet. Immunol. Immunopathol. 164:16-23. https://doi.org/10.1016/j .vetimm.2014.12.016.

NRC. 2001. Nutrient Requirements of Dairy Cattle. 7th rev. ed. National Academy Press, Washington, DC.

Oliveira, E. B., F. Cunha, R. Daetz, C. C. Figuereido, R. C. Chebel, J. E. Santos, C. A. Risco, K. C. Jeong, V. S. Machado, and K.
N. Galvão. 2020. Using chitosan microparticles to treat metritis in lactating dairy cows. J. Dairy Sci. https://doi.org/10.3168/jds .2019-18028.

Ospina, P. A., D. V. Nydam, T. Stokol, and T. R. Overton. 2010. Evaluation of nonesterified fatty acids and beta-hydroxybutyrate in transition dairy cattle in the northeastern United States: Critical thresholds for prediction of clinical diseases. J. Dairy Sci. 93:546-554. https://doi.org/10.3168/jds.2009-2277.

Piccardi, M., G. Romero, G. Veneranda, E. Castello, D. Romero, M. Balzarini, and G. A. Bó. 2016. Effect of puerperal metritis on reproductive and productive performance in dairy cows in Argentina. Theriogenology 85:887-893. https://doi.org/10.1016/j theriogenology.2015.10.038.

Pohl, A., S. Bertulat, S. Borchardt, O. Burfeind, and W. Heuwieser. 2016. Randomized, controlled clinical trial on the efficacy of nonsteroidal antiinflammatory drugs for the treatment of acute puerperal metritis in dairy cows. J. Dairy Sci. 99:8241-8249. https:// doi.org/10.3168/jds.2015-10775.

Pohl, A., O. Burfeind, and W. Heuwieser. 2015. The associations between postpartum serum haptoglobin concentration and metabolic status, calving difficulties, retained fetal membranes, and metritis. J. Dairy Sci. 98:4544-4551. https://doi.org/10.3168/jds.2014-9181.

Sannmann, I., O. Burfeind, R. Voigtsberger, and W. Heuwieser. 2013. Comparison of two monitoring and treatment strategies for cows with acute puerperal metritis. Theriogenology 79:961-969. https:/ /doi.org/10.1016/j.theriogenology.2013.01.016.

Sheldon, I. M., G. S. Lewis, S. LeBlanc, and R. O. Gilbert. 2006. Defining postpartum uterine disease in cattle. Theriogenology 65:1516-1530. https://doi.org/10.1016/j.theriogenology.2005.08 .021 .

Stangaferro, M. L., R. Wijma, L. S. Caixeta, M. A. Al-Abri, and J. O. Giordano. 2016. Use of rumination and activity monitoring for the identification of dairy cows with health disorders: Part III. Metritis. J. Dairy Sci. 99:7422-7433. https://doi.org/10.3168/jds .2016-11352.

Stojkov, J., M. A. G. von Keyserlingk, J. N. Marchant-Forde, and D. M. Weary. 2015. Assessment of visceral pain associated with metritis in dairy cows. J. Dairy Sci. 98:5352-5361. https://doi.org/10 $.3168 /$ jds.2014-9296.

Tenhagen, B. A., A. Helmbold, and W. Heuwieser. 2007. Effect of various degrees of dystocia in dairy cattle on calf viability, milk production, fertility and culling. J. Vet. Med. Ser. A Physiol. Pathol. Clin. Med. 54:98-102. https://doi.org/10.1111/j.1439-0442.2007 $.00850 . x$.

Vasquez, A. K., D. V. Nydam, C. Foditsch, M. Wieland, R. Lynch, S. Eicker, and P. D. Virkler. 2018. Use of a culture-independent on-farm algorithm to guide the use of selective dry-cow antibiotic therapy. J. Dairy Sci. 101:5345-5361. https://doi.org/10.3168/jds 2017-13807.

Vergara, C. F., D. Dopfer, N. B. Cook, K. V. Nordlund, J. A. A. McArt, D. V. Nydam, and G. R. Oetzel. 2014. Risk factors for postpartum problems in dairy cows: Explanatory and predictive modeling. J. Dairy Sci. 97:4127-4140. https://doi.org/10.3168/jds .2012-6440.

Vieira-Neto, A., F. S. Lima, J. E. P. Santos, R. D. Mingoti, G. S. Vasconcellos, C. A. Risco, and K. N. Galvao. 2016. Vulvovaginal laceration as a risk factor for uterine disease in postpartum dairy cows. J. Dairy Sci. 99:4629-4637. https://doi.org/10.3168/jds.2016 -10872 .

Wittrock, J. M., K. L. Proudfoot, D. M. Weary, and M. A. von Keyserlingk. 2011. Short communication: Metritis affects milk production and cull rate of Holstein multiparous and primiparous dairy cows differently. J. Dairy Sci. 94:2408-2412. https://doi.org/10.3168/ jds.2010-3697. 